\title{
Altmetrics data providers: A meta- analysis review of the coverage of metrics and publication
}

\author{
José-Luis Ortega
}

How to cite this article:

Ortega, José-Luis (2020). "Altmetrics data providers: A meta-analysis review of the coverage of metrics and publications". El profesional de la información, v. 29, n. 1, e290107.

https://doi.org/10.3145/epi.2020.ene.07

Invited manuscript received on November, $20^{\text {th }} 2019$ Accepted on December, $10^{\text {th }} 2019$

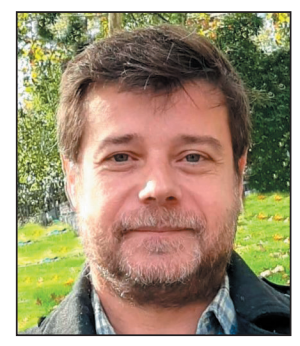

José-Luis Ortega $\square$

https://orcid.org/0000-0001-9857-1511

Institute for Advanced Social Studies (IESA-CSIC)

Joint Research Unit (CSIC-University of Córdoba)

Innovation, Knowledge and Transfer

Plaza Camposanto de los Mártires, 7.

14004 Córdoba, Spain

jortega@iesa.csic.es

\begin{abstract}
The aim of this paper is to review the current and most relevant literature on the use of altmetric providers since 2012. This review is supported by a meta-analysis of the coverage and metric counts obtained by more than 100 publications that have used these bibliographic platforms for altmetric studies. The article is the most comprehensive analysis of altmetric data providers (Lagotto, Altmetric.com, ImpactStory, Mendeley, PlumX, Crossref Event Data) and explores the coverage of publications, social media and events from a longitudinal view. Disciplinary differences were also analysed. The results show that most of the studies are based on Altmetric.com data. This provider is the service that captures most mentions from social media sites, blogs and news outlets. Plum X has better coverage, counting more Mendeley readers, but capturing fewer events. CED has a special coverage of mentions from Wikipedia, while Lagotto and ImpactStory are becoming disused products because of their limited reach.
\end{abstract}

\section{Keywords}

Altmetrics; Coverage; Data providers; Social media; Lagotto; Altmetric.com; ImpactStory; Mendeley; PlumX; Crossref Event Data; Wikipedia; Review.

\section{Introduction}

Altmetric data providers play a key role in altmetric research, to the point that much of this research topic relies on these providers in order to carry out most of their studies. The importance of these platforms is not only due they are fundamental tools for altmetric research, but also that data from these services are increasingly being used to evaluate articles, authors and organisations. It is worth remembering that Altmetric.com has mainly based its business on supplying metrics and indicators to academic publishers. Similarly, PlumX has found in the institutions the way to develop its activity, offering a dashboard to track the social impact of their outputs. This commercial activity has inserted their altmetric counts into the scholarly publishing environment prior to being tested as reliable and significant research indicators, causing considerable misinterpretation about their meanings and importance (Bornmann, 2014).

In this sense, altmetrics is obliged to test the reliability of these services both to verify that the scientific results are based on trustworthy sources and to audit the authenticity of these services as data providers. This vigilant attitude is even more motivated because these platforms are not exactly scientific instruments for bibliometric studies, but commercial suites focused on providing visibility to academic journals and organisations. Altmetrics should therefore be undertaken as an independent and authoritative instrument that assesses the technical suitability of these tools for supplying and processing altmetric counts. The clearest expression of this inspection attitude is the NISO Alternative assessment metrics (Altmetrics) initiative which aims to standardise and ensure transparency of the way in which data aggregators obtain and process their information (NISO, 2016). 
However, and despite all these platforms agreeing to report their sources and how they process their metrics, important points still need more clarification. For example, aggregators should improve their reporting of the complete list of sources covered, mainly blogs and news media; how they manage the intentional manipulation of metrics (i.e., bots on Twitter); and how the links to events are curated and updated when they are moved or eliminated (Ortega, 2019b). These limitations are evident when the resulting metrics are compared and the counts differ significantly, although many of them come from the same source such as Twitter, Mendeley or Wikipedia. These discrepancies raise doubts about the reliability of these platforms when they come to extract information and count metrics.

This instability in the metrics provided by each data aggregator justifies a meta-study to collect all the figures captured from these providers at different times and from different samples, enabling an accurate picture of how these services are evolving in time and a general overview of the coverage and working of each platform. It is interesting to note that this type of analysis is uncommon in bibliometric studies, even more when referring to a quantitative discipline. In altmetrics, we can highlight the study by Bornmann (2015a), who analysed the published correlations between tweets, blogs and readers. But, perhaps, the most exhaustive meta-analysis was performed by Erdt et al. (2016b). These authors reviewed the literature about altmetrics and performed a cross-metric validation of altmetric indicators. However, no meta-study has explored the evolution and coverage of altmetric data providers. This study attempts to fill this gap by reviewing the current altmetric literature and analysing the numbers obtained by these studies.

\section{Objectives}

The principal objective of this work is to review and analyse the scholarly literature that has used an altmetric provider to conduct its studies. The aim is to check and contrast the figures obtained to build a general picture of the coverage and metrics supplied by each altmetric provider. From this analysis, we aim to:

- describe the proportion of indexed publications (coverage) in each provider;

- present the proportion of documents in each provider by metric;

- depict the average counts of each metric; and

- display disciplinary differences by metric and provider.

\section{Methods}

\subsection{Altmetric providers}

Within the context of big data and its technological revolution, altmetric data providers or aggregators are platforms that capture, collect and quantify in a single venue different events about scholarly publications produced in distant places on the Web. According to commercial agreements or open endpoints, these secondary services are adding up events generated in social networks, specialised databases, citation indexes, blogs and news outlets. Using specific document identifiers (doi, isbn, uri, Pubmed id, etc.), these platforms track the footprint of a publication on each website that they monitor. In addition, these platforms sometimes produce indicators and reports from the information gathered, offering added value to the data provided. Mendeley is a special case because it is not strictly a data provider, but an online reference manager. However, this service is included because many studies have used this platform as a principal source for counting reader numbers.

\section{Mendeley}

https://www.mendeley.com

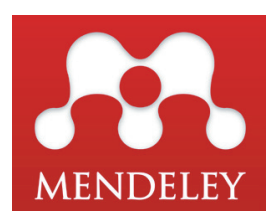

Lagotto http://www.lagotto.io

\section{Lagotto pios}

Lagotto was the first altmetric data provider and was created in March 2009 by the publisher Public Library of Science (PLOS). Although it is an open tool that can be used by any publisher, this instrument is not widespread, and only three publishers (PLOS, Copernicus and Public Knowledge Project) have implemented this provider. The last API version (Lagotto 4.0) dates from April 2015, an indication of its brief development. 


\section{Altmetric.com}

https://www.altmetric.com

Altmetric

Altmetric.com was launched in 2011 by Euan Adie, with the support of Digital Science. Altmetric.com is centred in the publishing world, signing agreements with publisher houses to monitor the altmetric impact of their publications. This information is accessible through a public API on the Web. Today, Altmetric.com captures over 60 million events and tracks the social impact of close to 9.5 million research papers (Altmetric.com, 2019).

ImpactStory

https://profiles.impactstory.org

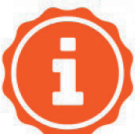

Impactstory

This aggregator was developed by Jason Priem and Heather Piwowar in 2011. Unlike other providers, ImpactStory is focused on building personal profiles that illustrate the altmetric impact of a researcher. Using Orcid and a Twitter account, this tool enables the creation of a profile with the list of publications mentioned on the Web. Up to 2015, this tool offered a public API to retrieve data, but this endpoint is now closed. To date, around 18,000 profiles have been created (ImpactStory, 2019).

\section{PlumX}

https://plu.mx/plum/g/samples

PlumX is a provider of alternative metrics created in 2012 by Andrea Michalek and Michael Buschman from Plum Analytics. This product targets the institutional market, offering altmetric counts of publications for specific institutions. PlumX is the aggregator that offers more metrics, including usage metrics (i.e. views and downloads). It covers more than 52.6 million artefacts and is the largest altmetric aggregator (Plum Analytics, 2019). In 2017, Plum Analytics was acquired by Elsevier and now tracks the online presence of any article indexed in the Scopus database. PlumX also offers their customers an API to extract data.

\section{Crossref Event Data (CED)}

https://www.crossref.org/services/event-data

CED is the youngest service. Created in 2016, it is still in beta. Unlike Altmetric.com and PlumX, CED is not a commercial site and provides free access to data through a public API. Another important difference is that it does not provide metrics, but only displays information about each altmetric event linked to a doi identifier. For instance, it shows information about an article mention on Twitter (date, user, tweet, etc.), but does not show a count of the number of tweets. For that reason, CED's data would have to be processed to be comparable with the other services. This provider is only accessible via API.

\subsection{Indicators}

One of the most important challenges of a meta-study is the selection and standardisation of the various observations for comparison and analysis. The observation date, when available, was used instead of the publication date to fairly compare different observations over time. In certain cases, although some metrics are not available in the paper, it includes enough information for that metric (percentages and proportions) to be calculated. In these cases, metrics were calculated and added to the study. Three main indicators were defined:

Coverage (\%): percentage of documents indexed in one provider. This percentage is available when an external sample was selected in the study and compared with the coverage of an altmetric service. This indicator reports the size of a data provider. Another way to refer to this metric are items with data scores (Gorraiz et al., 2018), nonzero altmetric events (Didegah et al., 2018) and nonzero scores (Thelwall, 2018).

Metrics proportion in each provider (\%): percentage of publications with at least one event from one metric in relation to the publications included in the provider. In this case, this indicator shows the weight of a metric over all the metrics gathered by one provider. This indicator is also named Percent nonzero (Thelwall; Nevill, 2018).

Average of events per publication: ratio of the total count of events by the number of indexed publications. This metric reports the frequency of each metric and is also named Geometric mean (Thelwall; Nevill, 2018) or Density (Zahedi et al., 2014b; Costas et al., 2015a; Gorraiz et al., 2018; 2019).

\subsection{Search criteria}

Google Scholar and Scopus were searched to obtain the sample of publications. The search criteria in both databases was a generic query "altmetric*" to obtain the largest number of results. After a first round, other precise queries were performed to identify papers that have used a data provider. For example, "altmetric" OR "altmetric.com" for Altmetric.com, "plumx" OR 
"Plum Analytics" for PlumX, "impactstory" for ImpactStory, "lagotto" OR "PLOS" for Lagotto, "crossref event data" OR "CED" for Crossref Event Data and "mendeley" for Mendeley. These results were filtered to search for papers that had used an altmetric data provider for their analysis, had calculated some of the previous indicators or had published any data that would allow us to compute them. A total of 107 articles published between 2012 and 2019 were selected for the study.

\section{Results}

First, the results describe the number of providers used, the coverage of publications and the percentage of papers mentioned in the most important metrics. Next, the number of counts of each metric in each provider will be presented, and lastly a disciplinary study will point out thematic differences among the aggregators.

\subsection{Providers}

Graph 1 illustrates the proportion of altmetric data providers used in the academic literature since 2012. This picture allows us to visualise how different providers gain market share and others fall into disuse. For example, the initial studies were done with Mendeley (50\%) and Lagotto (50\%). The first gives the source of the readers and the second the first altmetric provider. In 2013, Altmetric.com appeared as an altmetric source and began dominating the market. 2014 and 2015 are the years with more providers used

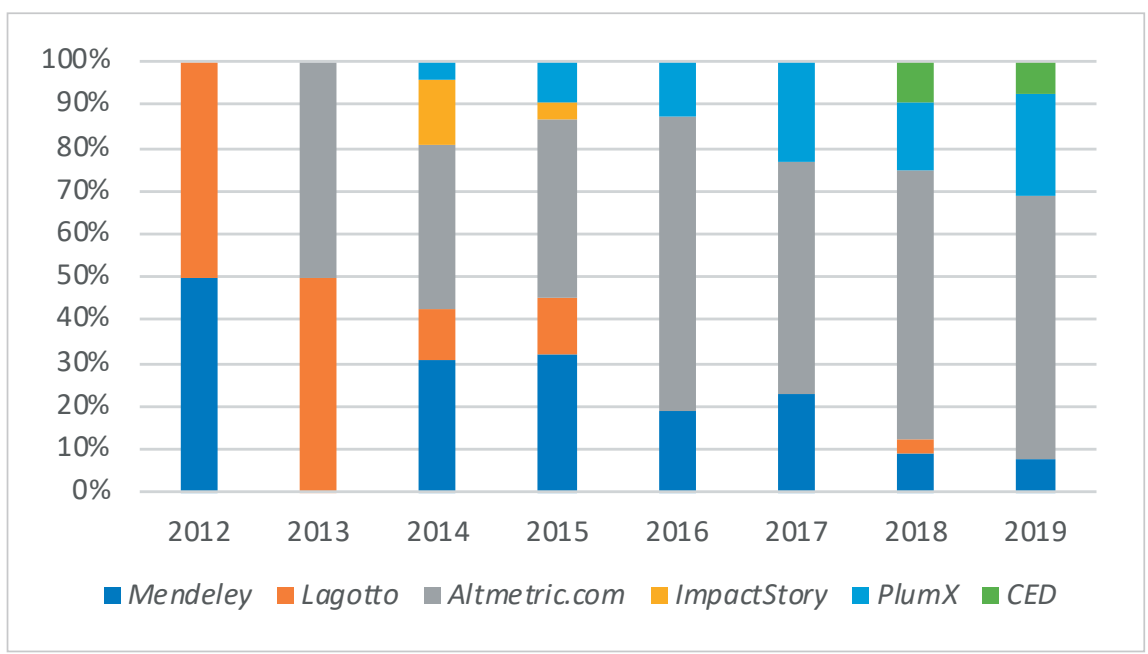

Graph 1. Proportion of data providers used in altmetric studies by year with the coming of Impactstory and PlumX. However, from 2016 to 2017 only three services were used, Mendeley, Altmetric.com and PlumX. Because Lagotto is not implemented in important publishers other than PLOS, it became a limited tool for altmetric studies and was used only in one-time cases (Zahedi; Costas, 2018). ImpactStory stops provide a public API, making it hard to obtain random representative samples. In 2018, a new data provider, Crossref Event Data, began being used and was the first non-commercial open product. Overall, the three main data sources are Altmetric.com (54\%), Mendeley (18\%) and PlumX (13\%), Altmetric.com being by far the most used service.

\subsection{Coverage}

Graph 2 depicts the distribution of publications covered in each data provider grouped by year. Lagotto was excluded due to absence of data. This trend was displayed using the data collection date, instead of the publication year because this is the closest date to the observation. However, not all the articles include that information and, in those cases, the publication date was selected, which could distort the results to some extent. We must therefore understand the data in an illustrative way. Another problem is that not all the observations were taken in the same way. Many are limited to specific disciplines, publication windows or regions, thereby provoking a high dispersal in

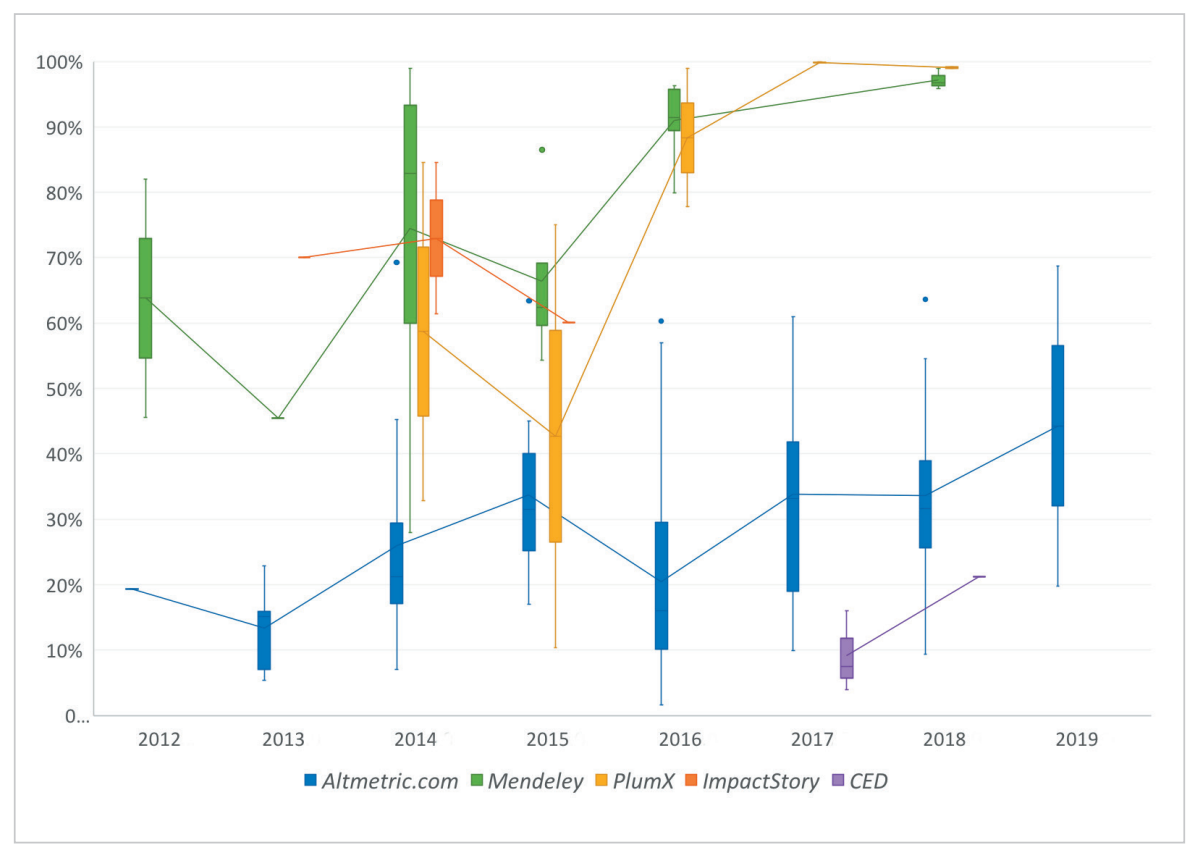

Graph 2. Yearly evolution of the coverage of the providers analysed annual distributions. 
Altmetric.com, the platform with most observations, shows a generalised, paused increase in the coverage of publications. Studies during the 2012-2013 period show a coverage between the 19.3\% of Knight (2014) and the $15.1 \%$ of Costas et al. (2015a). In 2014, these percentages slightly increased to a mean coverage of $28 \%$, where we can highlight the outlier 69.3\% (Bornmann, 2014a) caused by a sample of recommended papers in Biomedicine from F1000Prime. From 2015 to date, the mean coverage has stabilised around the $31.5 \%$ of 2015 , the $33.2 \%$ of 2017 and the $29.9 \%$ of 2018 . There was a fall in 2016 to $16 \%$ caused by some local studies about Brazilian publications (Eléspuru-Briceño; Huaroto, 2016; Maricato; Filho, 2018) where the indexation and mention of local publications was clearly insufficient (Alperin, 2015). In 2018, Orduña-Malea and Delgado-López-Cózar (2019) found the outlier 9.4\%. These authors used the full database of Dimensions to detect publications from Altmetric.com, with no time limit, including pre-2000 print documents that could not be mentioned in social networks. However, they reached $21.6 \%$ and $21.8 \%$ when they limited the sample to papers published in 2016 and 2017, respectively. Two recent studies (Wooldridge; King, 2019; Wolcott et al., 2019) place the coverage of Altmetric.com at $44 \%$ in 2019. The limited coverage observed in the literature is caused mainly by the fact that Altmetric.com only indexes publications previously mentioned in some social networks (Twitter, Facebook, Googlet, etc.) (Haustein et al., 2015; Bar-Ilan et al., 2019). This indexing strategy has resulted in the steady growth of coverage since 2014.

Mendeley, the second service by number of observations, describes a positive trend with continuous growth since 2013, reaching percentages of over $90 \%$ in 2016 . This high coverage is explained because the Mendeley Web Catalog is fed by important sources such as Pubmed, Scopus and their own users (Ortega, 2016), which brings an extensive number of publications. Thus, in 2012, Mendeley collected a mean of $63.8 \%$ of publications, ranging from the $82 \%$ of Bar-llan et al. (2012) to the $45.6 \%$ of Mohammadi et al. (2015). This considerable difference could be because the first study used a reduced sample of bibliometricians, which could overrepresent the number of readers. Mohammadi et al. (2015), however, take articles from 2008, when Mendeley was created. This early date could indicate that many articles are still not indexed in the platform. Later studies found similar percentages. Zahedi et al. (2014a; 2014d) also detected a coverage of $45.5 \%$ and $47.4 \%$ in a multidisciplinary sample. Mohammadi and Thelwall (2014) yielded low percentages: $28 \%$ for Humanities and 58\% for Social Sciences. Haustein and Larivière (2014), on the contrary, found 65.9\% in Biomedicine papers, which points to disciplinary differences in favour of the natural sciences. However, in mid-2014 an important change occurred in Mendeley's database because from that moment onwards the coverage percentages were always beyond $80 \%$. The most likely reason is the effective integration of the Scopus index in the Mendeley Web Catalog, which led to increased coverage of Mendeley (Bonasio, 2014; Scopus, 2014). In August 2014, Peters et al. (2014b) already detected $84.2 \%$ of coverage, while Bornmann and Haunschild (2015) found 99\% from F1000 papers. Subsequent studies (Thelwall; Wilson, 2016; Bornmann; Haunschild, 2016b) reported percentages over 90\%. In 2015, some disciplinary studies (Pooladian; Borrego, 2016; Aduku et al., 2017) showed that this high coverage is not the same in Computer Sciences (63.5\%), Engineering (54.3\%) or Library Sciences (61.4\%). From 2016, all the studies verified the elevated coverage of Mendeley with values higher than or around 90\% (Bornmann; Haunschild, 2017; Didegah et al., 2018; Zahedi; Van-Eck, 2018).

PlumX describes a growing trend motivated mainly by its integration into Elsevier's products such as Scopus, Mendeley and ScienceDirect from 2017. Until 2014, no studies used PlumX as a data source. The first was Peters et al. (2014b), who compared the coverage of several data providers using a sample of publications from Leibniz Association, finding 84.6\% of publications indexed in PlumX. However, this same team (Peters et al., 2016) observed 32.9\% when only datasets were considered. This percentage descended (10.4\%) when they repeated the same study one year later (Peters et al., 2015). From 2016 to 2019, coverage increases considerably to nearly 100\% (Meschede; Siebenlist, 2018; Zahedi; Costas, 2018; Ortega, 2018a; Ortega, 2019; Gorraiz et al., 2019). The only exception is Torres-Salinas et al., (2017a), who obtained a coverage of $77.7 \%$ because their sample was limited to books.

Studies on ImpactStory cover a short time-window (2013-2015). During this period, ImpactStory showed a mean coverage of between 70\% in 2013 (Zahedi et al., 2014b), 73\% in 2014 (Peters et al., 2014a; 2014b) and 60\% (Kraker et al., 2015) in 2015. CED also describes a short activity period (2017-2018), but with significant increases. Thus, in 2017, it showed an average coverage of 9.1\% (Ortega, 2018a; 2018b; Zahedi; Costas, 2018), which rose to 21.2\% in 2018 (Ortega, 2019 ).

\subsection{Coverage of metrics}

This section analyses the coverage of six of the most important metrics (tweets, readers, Wikipedia citations, Facebook mentions, blogs and news) according to each provider.

\subsubsection{Tweets}

Tweets are the most studied metric in the literature (62.3\%) because Twitter is the principal source of analyses of the dissemination and social impact of scholarly publications. Overall, Graph 3 shows that Altmetric.com is the platform that has continued for longer and with better mean percentages of tweets. Next, PlumX also shows a constant rise in tweets since 2016 but under Almetric.com counts. Other services such as Lagotto and ImpactStory present specific observations in short time periods. 
Altmetric.com presents a better and growing coverage of tweets, ranging from $10-15 \%$ in 2012 2014 to $40 \%$ in 2018 , on average. Coverage is better even though Altmetric.com's definition of the metric is restricted (it only counts the number of different users that tweeted a publication to avoid intentional manipulations), which a priori would produce lower values. The first studies were performed by Knight (2014), who detected $18.2 \%$ of tweeters for articles on solid organ transplantation in 2012. However, Adie and Roe (2013), analysing the full Altmetric.com database, reported that the coverage of tweets was still low (1.6\%). In 2013, Costas et al., (2015a) observed $13.3 \%$ of tweeters in a random sample of 500,000 WoS journal articles. In 2014 , average observation rose to $16.5 \%$, highlighting the outliers of

Haustein et al. (2014a) (44.9\%) and Alperin (2015) (0.8\%). The first was because the authors analysed 84,000 articles deposited in the online repository arXiv, which would favour the tweeting of these pre-prints. Contrary to this result, Alperin (2015) studied almost 400,000 articles from SciELO, a local database for Latin-American academic publications, evidencing the poor altmetric impact of Latin-American science or the incomplete coverage of Altmetric.com of local events in Spanish and Portuguese. In 2015, the coverage of tweets increased again (26.4\%), from $14 \%$ of publications about History in Htoo and $\mathrm{Na}$ (2015) and 41\% in Scott et al., (2015) from Pubmed articles. 2016 presents a similar mean percentage (26.8\%). Particularly noteworthy are the poor results of Eléspuru-Briceño and Huaroto (2016) (5.4\%) about documents deposited in the local repository of the Peruvian University of Applied Sciences (UPC) and those of Torres-Salinas et al. (2018b) (5.6\%) limited to publications from Spanish universities. Both studies based in local samples again provide evidence of the reduced impact on Twitter of local, non-English publications. At the other extreme, Wang et al. (2016) found 58\% of tweeted articles in a sample of Biotechnology articles authored by Chinese authors outside of China. This result could be explained by a research area exposed to social networks and that Chinese abroad could be inserted in prestigious groups and institutions. In 2017, the average proportion of tweeted documents (25.4\%) also caused

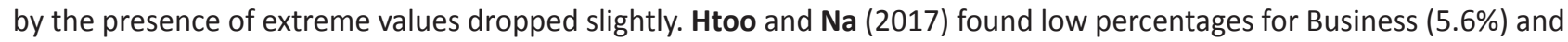
Law $(8.1 \%)$, confirming the low impact on Twitter of Humanistic disciplines. On the other hand, the highest values are for Zahedi and Costas (2018) (57\%), who used sample PLOS articles, which could indicate a greater exposure of PLoS journals on Twitter than other publications. In 2018, Altmetric.com increased considerably with a mean coverage of $40.8 \%$ of publications in Twitter. This observation encompasses the $26.9 \%$ of Economics and the $50.7 \%$ of Communication captured by De-Filippo and Sanz-Casado (2018). This result demonstrates the important disparity within the Social Sciences.

Next, PlumX also describes a positive evolution, starting from a mean of 6.6\% in 2016 to $33.5 \%$ in 2019 . The first observations about tweets on PlumX were done by Peters et al., (2014b) when they compared the presence of the Leibniz Association's publications in several aggregators. The results show insignificant percentages ( $<1 \%)$, which suggested that PlumX had technical problems to retrieve mentions from Twitter. However, one year later, Kraker et al. (2015), exploring the altmetric impact of datasets in PlumX and ImpactStory, uncovered a great proportion of files mentioned on Twitter (44.5\%). This dramatic improvement could be due to the employment of Gnip, the official provider of Twitter (Allen, 2015). Even so, this figure seems excessive and could be caused by bias due to the small sample size (757 datasets). This perception is based on the following percentages from 2016 onwards, more continued in time and less variable. That year, the mean percentage was $7.7 \%$, which fits with the $8.2 \%$ of Ortega (2016b), who studied the tweeting of articles from authors on Twitter. However, other studies showed different numbers. Meschede and Siebenlist (2018) detected 20.6\% when they compared a random sample of WoS articles in PlumX and Altmetric.com, whereas Torres-Salinas et al. (2017a; 2017b) perceived a very low percentage in two samples of books (1.4\% and $0.4 \%)$. This indicates that the mention of books on Twitter is scarcer than journal articles. In 2017, the mean percentage rose considerably (24.5\%). That year, the lowest value was found by Ortega (2018b) when analysing 67,000 articles from PlumX (17.6\%), while Bar-Ilan et al. (2019) noticed $30.2 \%$ in 2,700 articles from the Journal of the Association for Information Science and Technology. 
This result suggests that Information Sciences could gain more attention on Twitter than the average. In 2018, the mean percentage was $30.8 \%$, thanks to Gorraiz et al. (2018), who analysed the Austrian publications in PlumX and found $25.4 \%$ and 36.7\% for publications mentioned on Twitter for 2014 and 2016, respectively. The last observation, in 2019, was repeated by these same authors (Gorraiz et al., 2019), but only with regard to University of Vienna publications. The result $(32.7 \%)$ is just slightly higher than the previous year.

ImpactStory shows observations only in the 2013-2015 period. The trend was steady and homogenous, starting from an average percentage of tweeted papers of 1.3\% in 2013 (Zahedi et al., 2014b) and 7.8\% in 2014 (Peters et al., 2014b) to $14.6 \%$ in 2015 (Kraker et al., 2015). Lagotto also includes only a few observations, although it reached an average of $35.8 \%$ in 2015 and $51.1 \%$ in 2014 . This elevated proportion is due to the fact that Lagotto is almost solely implemented in PLOS journals. PLoS one, the multidisciplinary journal, has considerable exposure on Twitter, thereby giving rise to these high percentages. For example, Fenner (2013), analysing only the journal PLoS biology, detected just $14 \%$ of tweeted articles. Zahedi et al. (2015a) detected the derisory $0.1 \%$ of tweeted articles in Lagotto using a random sample of Crossref. For CED, only the studies by Ortega (2018b) and Zahedi and Costas (2018), carried out in 2017, can be mentioned. Both found very low percentages: $1.3 \%$ for Ortega (2018b) and 1.7\% for Zahedi and Costas (2018).

\subsubsection{Readers}

Another of the most studied metrics is the number of Mendeley readers with a publication (54.7\%). The reason for this interest is the strong association of this metric with bibliographic citations (Mohammadi; Thelwall, 2014) and its possible utilisation as an indicator of early scientific impact (Thelwall; Nevill, 2018). Graph 4 depicts an increasing evolution in every provider, more defined from 2016 onwards. Mendeley is obviously the platform that has a better coverage of readers, with a continued rise in readers since 2014. Next, PlumX is the service with better percentages in relation to Altmetric.com, mainly from 2016.

Altmetric.com is the service that presents a less average proportion of readers in comparison to the other aggregators. The first observation came in 2012 from Knight (2014), who observed 12.9\% of readers in Medicine papers from Scopus. But up to 2014 , there is no study on the coverage of readers by Altmetric.com. In that year, the mean percentage of readers in Altmetric.com grew to $16.3 \%$, although the observations vary considerably. Hammarfelt (2014) noticed that $7.4 \%$ of books have at least one Mendeley reader. Robinson-García et al. (2014) showed a little higher percentage (12\%) in a very large random sample of 2.8 million papers from WoS. Peters et al. (2014b) detected a range of readers from $8.6 \%$ in Humanities to $20.6 \%$ in the Life Sciences. However, Zahedi et al. (2014c) observed a surprising $46 \%$ due, perhaps, to the sample being set up by PLOS one papers, which could indicate that multidisciplinary journals have more saves in Mendeley (Zahedi et al., $2014 b)$. In 2015, the number of readers covered by Altmetric.com rose to $25.1 \%$. Observations are now more stable and the $38.9 \%$ of readers in Psychology and the $11.8 \%$ in History are worth mentioning (Htoo; $\mathbf{N a}, 2015)$. Other studies present similar percentages (Alhoori et al., 2015; Zahedi et al., 2015a; Nuredini; Peters, 2016; Thelwall; Nevill, 2018). In 2016, the articles by Meschede and Siebenlist (2018) and Torres-Salinas et al. (2018b) reached very similar percentages: $38 \%$ and $38.5 \%$, respectively, which confirms the increasing coverage of readers by Altmetric.com. In 2017, the mean percentage fell to $28.8 \%$, as a result of the study by $\mathbf{H t o o}$ and $\mathbf{N a ~ ( 2 0 1 7 ) ~ a b o u t ~ t h e ~ d i s c i p l i n a r y ~ d i f f e r e n c e s ~ i n ~ a l t m e t r i c s ~ f o r ~ S o c i a l ~ S c i e n c e s , ~}$ when they verified the low number of readers in some disciplines such as Business (6.9\%) and Law (8.3\%). Excepting this study, the percentages uniformly increase again, from the $40.1 \%$ of Ortega (2018b) and $40.8 \%$ of Bar-llan et al. (2019) to the $60.6 \%$ of Zahedi and Costas (2018). This last high value is based on PLoS articles, which could pinpoint a bias in favour of PLoS articles in Mendeley, as was seen in Zahedi et al. (2014c; 2014b). In 2018, these values remain stable between the $40.8 \%$ of Repiso et al. (2019) and the $42.4 \%$ of Bar-llan et al. (2019). However, Torres-Salinas et al. (2018a) found $20.4 \%$ of readers in books, indicating the low coverage of books by Mendeley. 
After Mendeley, PlumX is the aggregator with a better coverage of readers. In 2014, the first study with PlumX data (Peters et al., 2014b) already noted an elevated coverage from the $61.7 \%$ in Humanities to the $88.1 \%$ in Life Sciences. However, the study by Kraker et al. (2015), limited to Figshare objects, brought an anecdotal 2.2\% of readers. In 2016, there was great variability between the results of Meschede and Siebenlist (2018) (91.3\%) and the outputs of Torres-Salinas et al. (2017a; 2017b) (15.2\%; 24.2\%). The latter studies were restricted to books, indicating poor coverage and reading of books in Mendeley as in Altmetric.com (Torres-Salinas et al., 2018a). In 2017, the average number of readers grew dramatically (79.1\%), thanks to studies by Bar-llan et al. (2019) (63.1\%), Ortega (2018b) (77.7\%) and Zahedi and Costas (2018) (96.6\%). This trend was reinforced in 2018 (89.4\%) and 2019 (88.7\%) with the results of Ortega (2018b), Zahedi; Costas (2018), Bar-Ilan et al. (2019) and Gorraiz et al. (2018; 2019).

Mendeley is the service that produces the metric readers and, consequently, the coverage of papers in Mendeley (Graph 2 ) is similar to the trend of the number of papers with at least one reader (Graph 4). Even so, some studies have evidenced that not all the references included in Mendeley have readers, so these pictures would not match exactly (Mohammadi et al., 2015; Bornmann; Haunschild, 2016b; 2017). As mentioned in the section on coverage, Mendeley presents a low proportion of readers between 2012 and 2014, the mean being 65.9\% in 2012 (Haustein et al., 2014b; Mohammadi et al., 2015) and 45.5\% in 2013 (Zahedi et al., 2014a). As with coverage, the percentage of readers in Mendeley increases considerably in the middle of 2014, with values beyond 75\% (Peters et al., 2014b; Bornmann; Haunschild, 2016b; Thelwall; Wilson, 2016). In 2015, the average of readers reached 75.1\% and in 2016, 96.1\%. Finally, in 2018 it was near to $100 \%$ (98.15\%) (Didegah et al., 2018; Bar-llan et al., 2019; D’Angelo; Di-Russo, 2019).

Studies that used ImpactStory show a good coverage of readers. In 2013, Zahedi et al. (2014b) uncovered an average of articles with $57.3 \%$ of readers, more than the $45.5 \%$ of Zahedi et al. (2014a), using Mendeley. This difference could be attributed to different samples and ways of matching the data (i.e. articles with/without doi). Peters et al. (2014b) maintained this percentage in 2015 (59.8\%) and Kraker et al. (2015) fell to 1\% when they studied the readers of Figshare datasets. Lagotto showed a high 72.2\% average of readers in 2014 (Zahedi et al., 2014c; Bornmann, 2014b; 2015). These elevated values are again due to PLoS one, which attracts more attention than average, distorting the coverage of this provider. In 2015, this percentage descended to $46 \%$ with the analysis by Zahedi et al. (2015a).

\subsubsection{Wikipedia}

Wikipedia's citations are an important metric that describes the educational impact of scientific research (Kousha; TheIwall, 2017). However, it is a metric with a low prevalence because it requires the writing of an entry and an important selection of the most relevant bibliography. Graph 5 presents the evolution of the percentage of articles with a Wikipedia citation included in each provider. Percentages do not exceed $7 \%$ in all the aggregators. Altmetric.com and PlumX describe a steady increase since 2015, caused by the growth of the online encyclopaedia and the addition of different language versions. Thus, the first study on the coverage of Wikipedia citations in Altmetric.com was performed in 2015 by Nuredini and Peters (2016), who observed a 1.1\% of papers with mentions, and Thelwall and Nevill (2018) with $0.2 \%$. These proportions increased by $1.3 \%$ in 2016 and $2.4 \%$ in 2017. In 2018, there is a slight descent (1.7\%) caused by the low percentages found by De-Filippo and Sanz-Casado (2018) (1.6\% and 1\%) and Repiso et al. (2019) (1.3\%). These results are due to the fact they are analysing Social Sciences disciplines, which would indicate fewer Wikipedia mentions to that research area than to others (Zahedi et al., 2014b). In 2018, Torres-Salinas et al. (2018a) found a disproportionate $11.7 \%$ of Wikipedia mentions caused by a sample based on books from Book Citation Index (WoS). This result suggests that books are specially mentioned in Wikipedia, due perhaps to the educational orientation of the monographs.

PlumX also describes a constant growth since the first observation by Peters et al. (2014b) (0.7\%) in 2014 to the last by Gorraiz et al. (2019) (3\%) in 2019. This signifi-

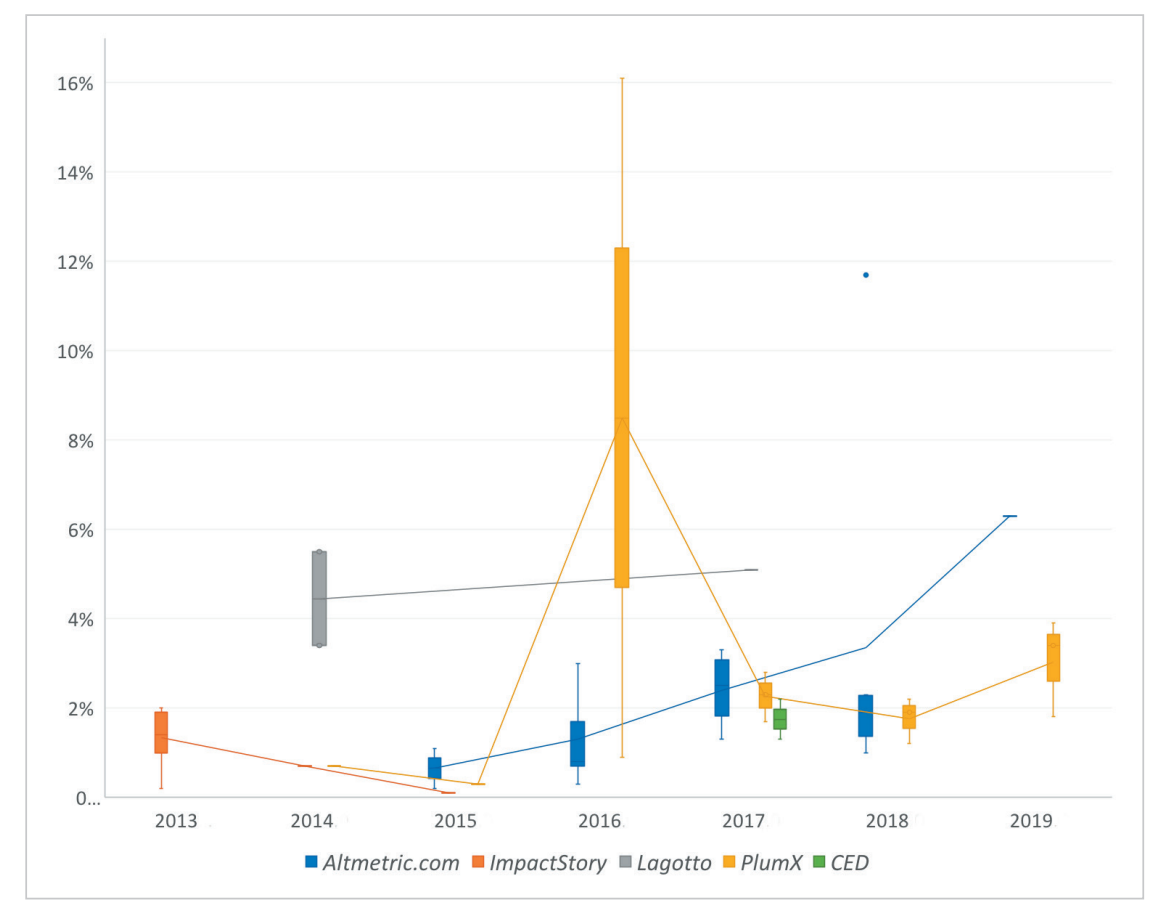

Graph 5. Yearly evolution of the percentage of Wikipedia's citations in each provider 
cant increase could be due to the indexation of entries in languages other than English (Allen, 2018). It is important to notice that in 2016 Torres-Salinas et al. (2017b) found the astonishing proportion of $16 \%$ of Wikipedia citations in a sample of books, close to the $11.7 \%$ in Altmetric.com (Torres-Salinas et al., 2018a), which would confirm that books are more cited in Wikipedia than research papers (Kousha; Thelwall, 2017). ImpactStory presents a downward trend, starting from a $1.3 \%$ of citations on average in 2013 to the $0.7 \%$ of Peters et al., (2014b) in 2014 and the $0.1 \%$ of Kraker et al. (2015). Lagotto again shows a high main percentage (4.5\%) because it is only representative of PLoS journals. Lastly, CED was used in 2017 (Ortega, 2018b; Zahedi; Costas, 2018), resulting in an average of 1.7\%, similar to PlumX and Altmetric. com in that year.

\subsubsection{Facebook}

Facebook's mentions are other important metrics resulting from a generalist social network. It counts the number of mentions, shares and likes that a publication receives. However, when aggregators come to count Facebook mentions, there are differences between them, which could produce inconsistencies in the comparison. Altmetric.com only includes posts on a curated list of public pages, excluding likes and individual pages (Altmetric Support, 2019). PlumX and Lagotto, on the contrary, index and add likes, comments and shares in a single count (Allen, 2016; PLoS, 2019). Taking these facts into consideration, Graph 6 presents a constant increase of Facebook mentions, mainly in Altmetric. com and PlumX. Altmetric.com evolves positively from the average mentions of $1.3 \%$ in 2012 (Adie; Roe, 2013; Knight, 2014) to the 9.2\% in 2018 (De-Filippo; Sanz-Casado, 2018; Repiso et al., 2019; Robinson-García et al., 2019) and 9.6\% in 2019 (Wooldridge; King, 2019). PlumX follows a similar ascending pattern (on average, $7 \%$ in 2014 to $9.8 \%$ in 2018), but with more peaks and troughs. Thus, the highest outlier observation is the $16.3 \%$ found by Zahedi and Costas (2018), due to the use of a limited sample of PLOS articles. As we have seen before, articles from that publisher present higher than average values in social media metrics. It is interesting that despite PlumX counting more Facebook events, the percentage of articles mentioned is very similar to Altmetric. com. According to ImpactStory and Lagotto, the observations are anecdotal, with the $0.3 \%$ (Peters et al., 2014b) in 2014 and the 0.9\% (Kraker et al., 2015) in 2015 of ImpactStory being the most noteworthy. Lagotto describes very high values (45.4\% in 2014) arising from the fact that PLoS articles have a better presence in social networks. Lagotto figures are not depicted in the graph be-

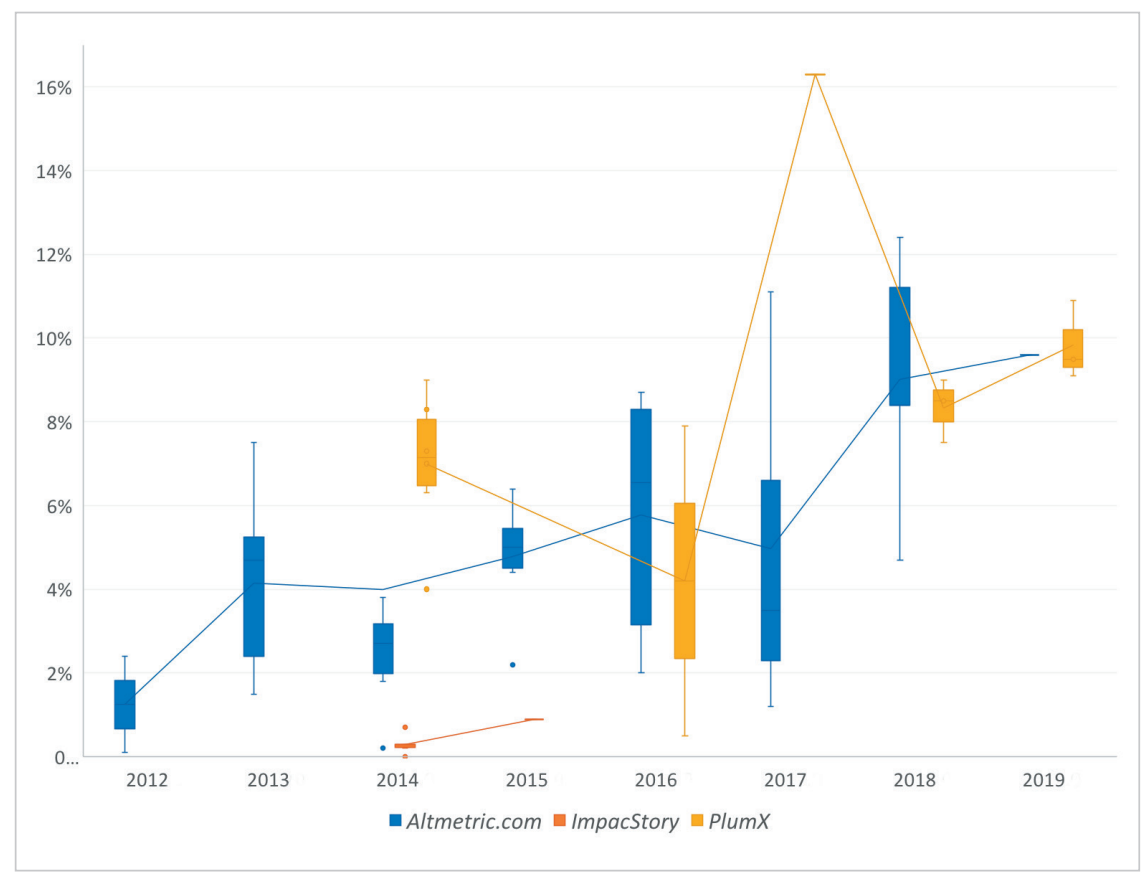

Graph 6. Yearly evolution of the percentage of Facebook's mentions in each provider

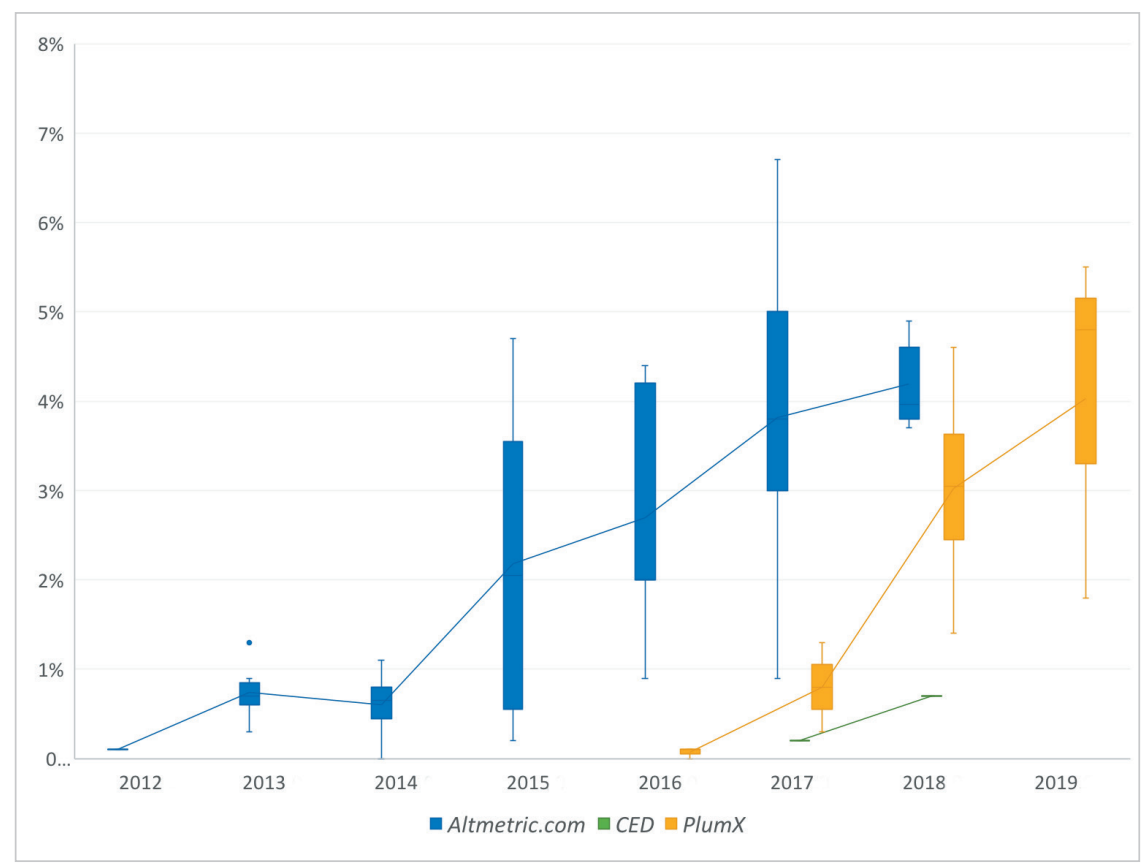

Graph 7. Yearly evolution of the percentage of news' mentions in each provider 
cause of the considerable distortion they cause.

\subsubsection{News}

News mentions measures the number of times that a research publication is mentioned in a news outlet. Unlike the other metrics, this one is not based on a single source. Rather, it depends on the coverage of news media that each provider gets indexing, which can give rise to important differences between services. Graph 7 describes a steady increase of news events in each provider, especially in the last three years. Only three services (Altmetric.com, PlumX and CED) were used in the literature to extract news mentions. Altmetric.com presents a paused growth up to 2017, starting from the $0.1 \%$ of Knight (2014) in 2012 to the mean 3.8\% in 2017. Graph 7 shows a jump from 2015, motivated by the new partnership with Moreover.com (Williams, 2015), which doubles the proportion of mentioned articles on news media. In 2018, the coverage of news increased to the mean of 4.2\% (Repiso et al., 2019; Dardas et al., 2018; Torres-Salinas et al., 2018a; Ortega, 2019; Robinson-García et al., 2019). PlumX showed more continued growth, ranging from $0.1 \%$ in 2016 (Meschede; Siebenlist, 2018; Torres-Salinas et al., 2017a; 2017b) to 4\% in 2019 (Gorraiz et al., 2019). According to CED, Ortega's papers show a coverage of $0.2 \%$ in 2017 (Ortega, 2018b) and of $0.7 \%$ in 2018 (Ortega, 2019), considerably lower than PlumX and Altmetric.com, which have similar percentages.

\subsubsection{Blogs}

The last metric analysed is the number of references to scholarly outputs included in Blogs. In the manner of News, this indicator is also influenced by the list of sources managed by each provider. Graph 8 illustrates the evolution of the percentage of publications with that metric in each provider. Overall, the percentage of mentioned articles increased in every service during the period covered. Altmetric.com describes a constant rise in mentions, from $0.6 \%$ for Knight (2014) in 2012 to the $8.8 \%$ average mentions in 2018. Throughout this time span, worthy of notice is the $0 \%$ of Latin-American articles mentioned in 2014 by Alperin (2015), which illustrates the low presence of non-English literature in altmetric aggregators. Also interesting is the significant coverage of articles on Psychology (8.2\%) reported by Htoo and $\mathrm{Na}$ (2015) and Business (6.4\%) by Nuredini and Peters (2016) in 2015. This result could be due to the important presence of blogs specialising in Social Sciences subjects such as Psychology, Economics and Politics (Ortega, 2019c). The growth of the

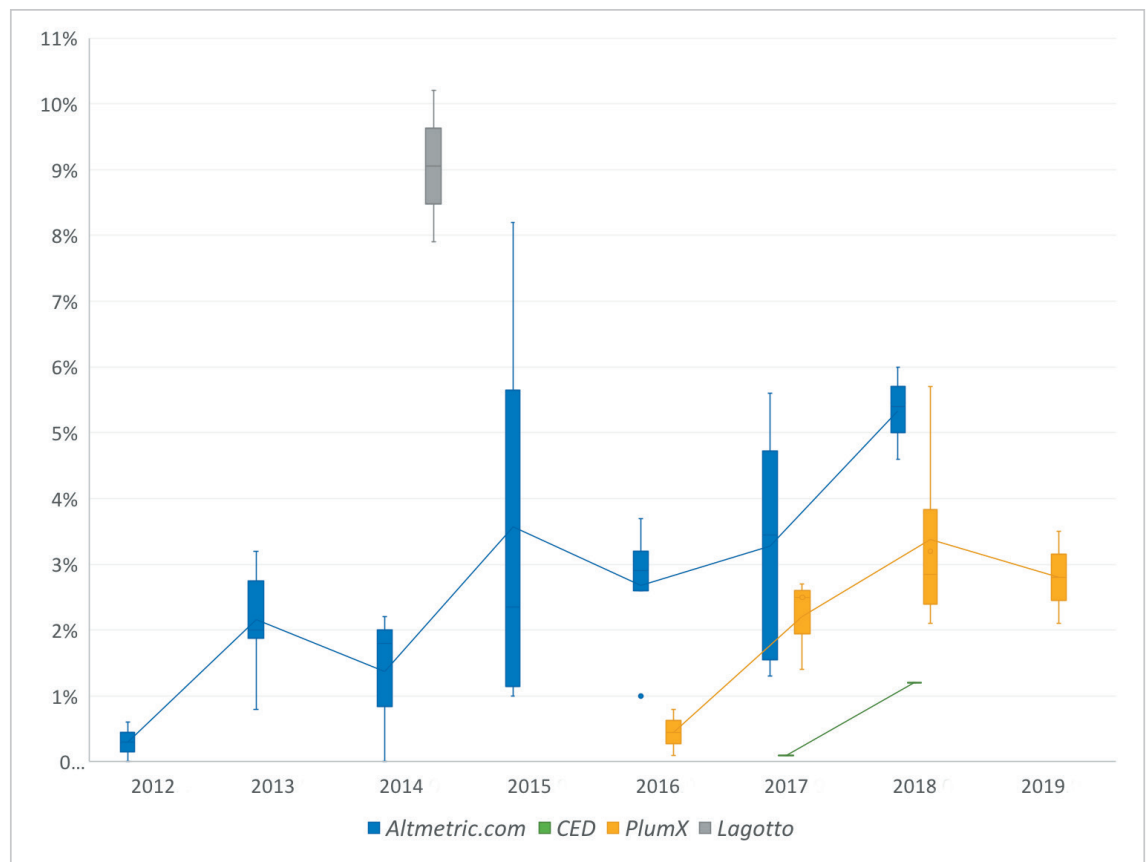

Graph 8. Yearly evolution of the percentage of blog mentions in each provider percentage of blog mentions in PlumX is also continuous. Since 2016, the mean percentage of blogs mentions has increased from $0.8 \%$ to close to $3 \%$ in 2019. In this period, the high value observed by Ortega (2019a) (5.8\%) is noteworthy. According to other providers, Lagotto presents an elevated proportion (9\%) due to the aforementioned high presence of PLoS journals on social media. CED describes an increasing coverage of publications from 0.1\% in 2017 (Ortega, 2018b) to 1.2\% in 2018 (Ortega, 2019a).

\subsection{Metrics proportion in each provider}

This section describes the coverage and weight of the different metrics in each provider. The aim is to observe differences between services when they come to capture each metric.

Graph 9 depicts the distribution of the percentages of the eight most important metrics observed in the literature by altmetric provider. In general, Altmetric.com presents higher coverage in every metric with the exception of Facebook mentions, Mendeley readers and Wikipedia citations. In the case of Facebook, Lagotto captures more mentions (18.5\%) than Altmetric.com (15.6\%) and PlumX (9\%), caused mainly by the high coverage of PLoS articles in social networks (Priem et al., 2012; Fenner, 2013; Zahedi; Costas, 2018). The distribution of Mendeley readers in each aggregator is skewed due to different sample size and type. This is especially significant in the study of books, where the proportion of readers is very 
low with regard to articles (Torres-Salinas et al., 2017b; 2018a). These authors found between 20.4\% (Altmetric. com) and $48.8 \%$ (PlumX) of readers. Leaving these counts aside, PlumX is the platform that captures a higher proportion of Mendeley readers (93.8\%), followed by Lagotto (87.5\%) and Altmetric.com (80.9\%). Mentions on Twitter also follow a skewed distribution with many outliers. In the case of Altmetric.com, it is important to notice the first observation of Adie and Roe (2013) when the service had just started (1.5\%); tweets to books (Torres-Salinas et al., 2018a) (26.2\%); geographical and language biases in Spanish (Torres-Salinas et al., (2018b) (13\%) and Latin-American articles (Alperin, 2015) (24.2\%); and disciplinary differences in nursing (Dardas et al., 2018) (23.8\%) and dentistry (Kolahi et al., 2017) (21.5\%). In spite of these values, Altmetric.com is by far the aggregator that gathers the most Twitter mentions $(72.5 \%)$, followed by $L a$ gotto (30.4\%). PlumX gathers $29.2 \%$ on average, excepting books (Torres-Salinas et al., 2017a; 2017b) and the study of Peters et al. (2014b), when PlumX did not yet use Gnip to extract Twitter citations. CED includes an average of $28.7 \%$ of tweeted papers. Lastly, the coverage of Wikipedia citations by CED is especially relevant because it is the service that has a greater percentage of articles cited on Wikipedia $(31.2 \%)$. This is mainly becau-

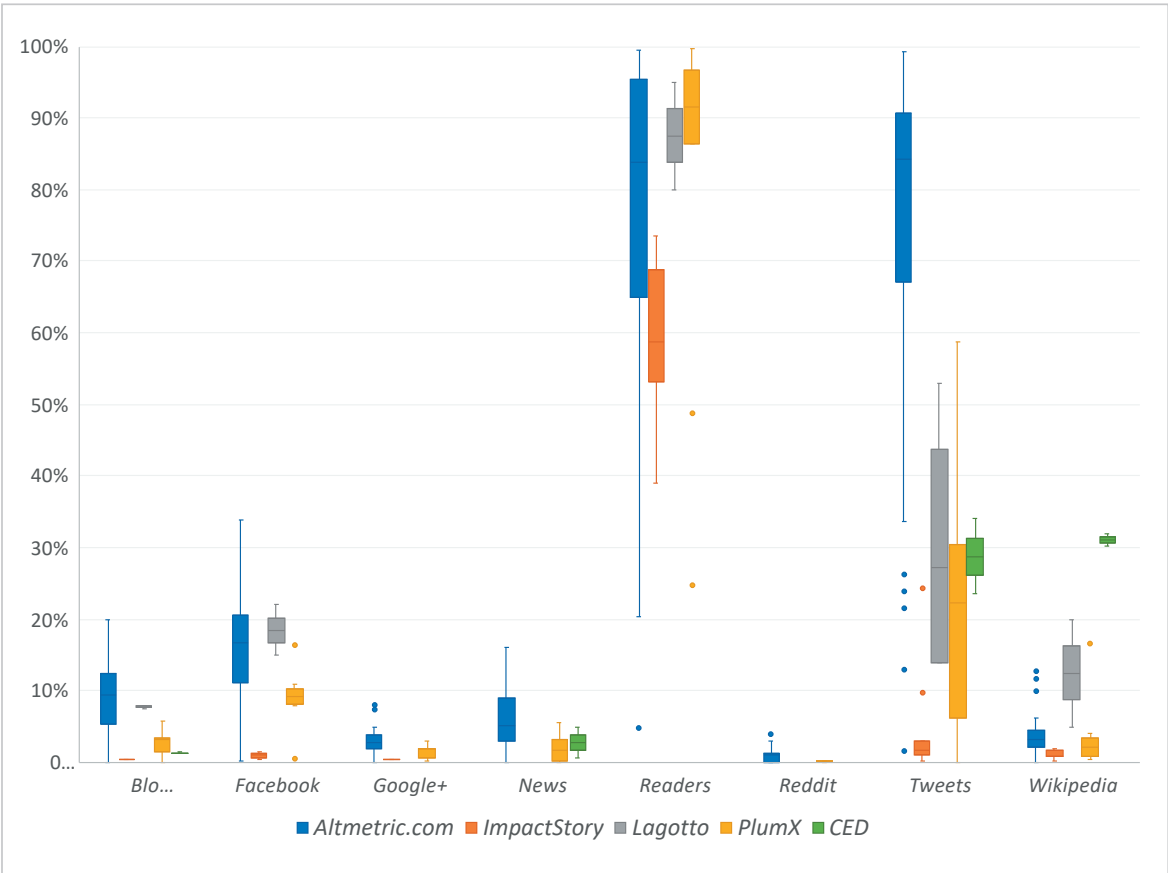

Graph 9. Box plot of the most important metrics by altmetric provider

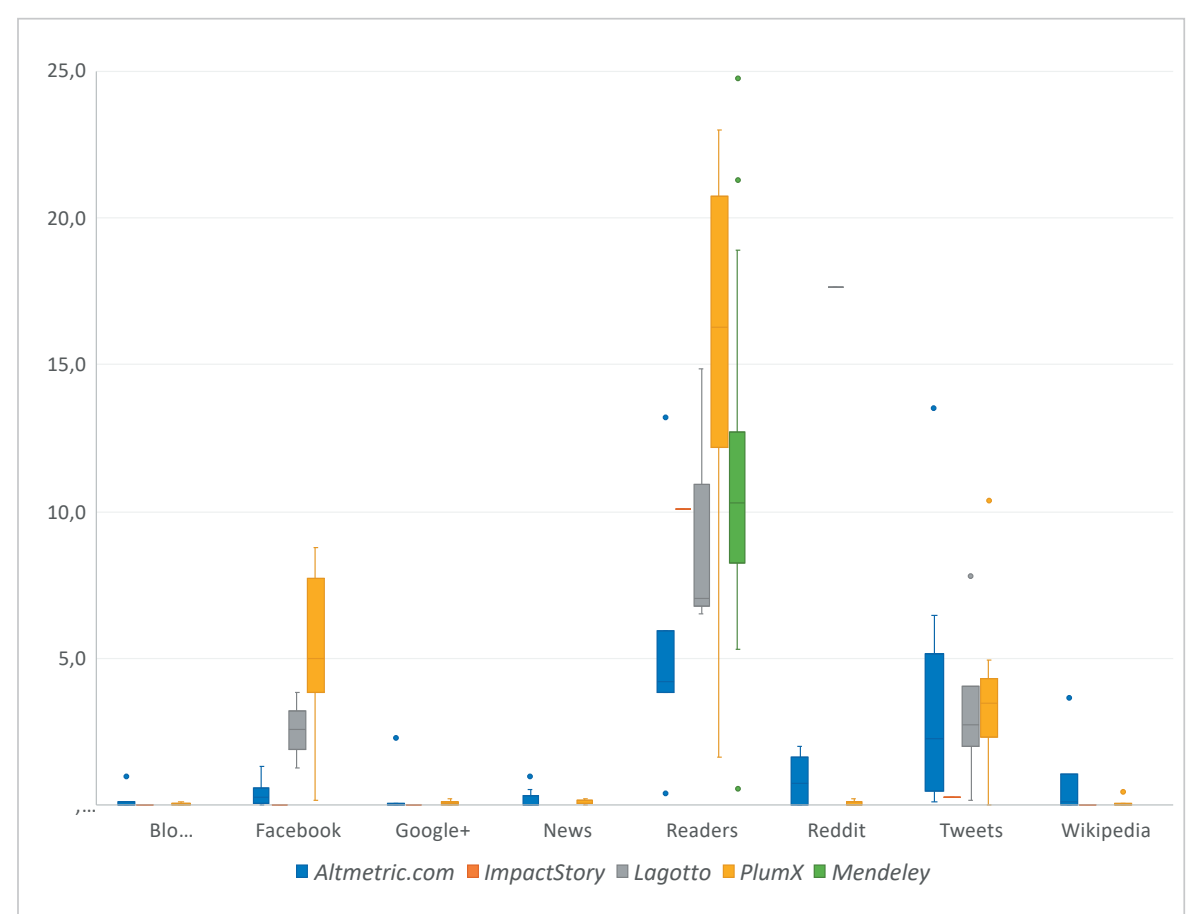

Graph 10. Box plot of the frequency of events by paper according to provider se it harvests entries from across Wikipedia, with no language limitation (Ortega, 2018b; Zahedi; Costas, 2018).

\subsection{Average of events per publication}

This indicator illustrates the frequency at which a paper is mentioned in different metrics. This measurement offers information on the prevalence of events in every metric. It is calculated as the number of total events divided by the number of publications in the sample.

This indicator describes a high level of scattering resulting from both the heterogeneous nature of the samples and time and disciplinary differences. However, it is more stable when it comes to compare results across platforms. For this reason, only multidisciplinary samples were used to analyse this measure. Graph 10 presents a low proportion of events in almost every metric, with the exception of Facebook mentions, Mendeley readers and tweets. The remaining metrics do not amount to 10 mentions on average. Altmetric.com is the service that has a better proportion of events 
per publication across all metrics, excepting Facebook and readers. In the case of Facebook mentions, the average of events in PlumX (4.9) and Lagotto (2.6) is far greater than ImpactStory (0.03) and Altmetric.com (0.4). The reason for this discrepancy is that PlumX and Lagotto include likes and shares as Facebook mentions (Peters et al., 2014b; Allen, 2016; PLOS, 2019), causing an increase in the proportion of events by publication. More variability and higher complexity are found in the proportion of readers by provider. The average of events per publication in Mendeley (10.3) is lower than that observed in PlumX (15.5) and very similar to Lagotto (10.7) and ImpactStory (9.47). The higher proportion in PlumX is paradoxically explained by the fact that PlumX groups duplicated articles, causing the average of readers by publication to be higher than with non-merged references. However, worth noting is the outlier in Mendeley of Alperin (2015), who detected 0.6 of readers per publication in a sample of Latin-American publications. This low proportion could again suggest a bias detrimental to non-English papers. On the contrary, the proportion of 21.5 readers found by Bornmann and Haunschild (2016b) refers to review articles, which explains why this type of publication attracts a high proportion of readers. According to tweets, PlumX (3.5), Lagotto (3.4) and Altmetric.com (3.3) depict similar averages of mentions by publication, which suggests that these providers do not present significant differences in counting tweets per article. These percentages change when the most recent articles are observed (2018-2019). In this case, PlumX has 4.5 and Altmetric.com has 4 tweets per article. Nevertheless, some outliers influence these figures. Bornmann (2015) observed an elevated proportion of tweets (7.8) to recommended articles on F1000, a fact that could influence the mention of these articles on Twitter. Also interesting to note is the recent study by Gorraiz et al. (2019), who found 10.3 tweets per article in publications from the University of Vienna. This study confirms the increase in the number of tweets per article in recent years.

\subsection{Disciplines}

This section examines disciplinary differences in the coverage of publications in each provider and explores how each metric is distributed in different disciplines. All Science Journal Classification (ASJC) was used to group the different disciplinary studies (https://pg.edu.pl/documents/611754/75313317/asjc).

From this classification, Social Science and Humanities and Physical Sciences and Engineering were broken up to observe the specific behaviour of these categories: 52 (49\%) articles from the sample show some disciplinary information and only $18(17 \%)$ include data from providers other than Altmetric.com. This lack of data means that most of the results are only based on one or two observations, which could lead to inaccurate results and cautious interpretation.

The disciplinary coverage of publications has been studied in only three providers, Altmetric.com, Mendeley and ImpactStory. The remaining were used to track the coverage of specific metrics but not the general coverage of these platforms. The reason is that some providers were limited to specific sources (Lagotto) or to particular institutions (PlumX). Graph 11 presents the distribution of each research area according to the three providers analysed. In general, only two research areas present significant differences: Health Science and Social Sciences. Health Sciences describes higher coverage levels in all three providers. In the case of Altmetric.com, this proportion goes from the 19.3\% of Knight (2014) to the $69.3 \%$ of Bornmann (2014a), with an average of 38\%. Mendeley has better coverage, reaching $87.5 \%$ of articles. Interesting to note is the outlier of Haustein and Larivière (2014) with a $65.9 \%$, due mainly to the fact that this study is previous to Mendeley's integration with Scopus (Bonasio, 2014; Scopus, 2014). In the case of ImpactStory, only one publication contained information about its disciplinary coverage (Zahedi et al., 2014b). Thus, this platform captures $36 \%$ of Health Sciences papers. Interestingly, Social Sciences (25.7\%) and Humanities $(22.8 \%)$ have on average more publications included in Altmetric.com than the remaining areas. However, this pattern is not observed in Mendeley, where Life Sciences (95.7\%) and Physical Sciences (85\%) are the research areas that have more documents (Zahedi; Van-Eck, 2018). These differences between Mendeley and Altmetric.com could be because Altmetric.com only captures publications that have previously been mentioned in social

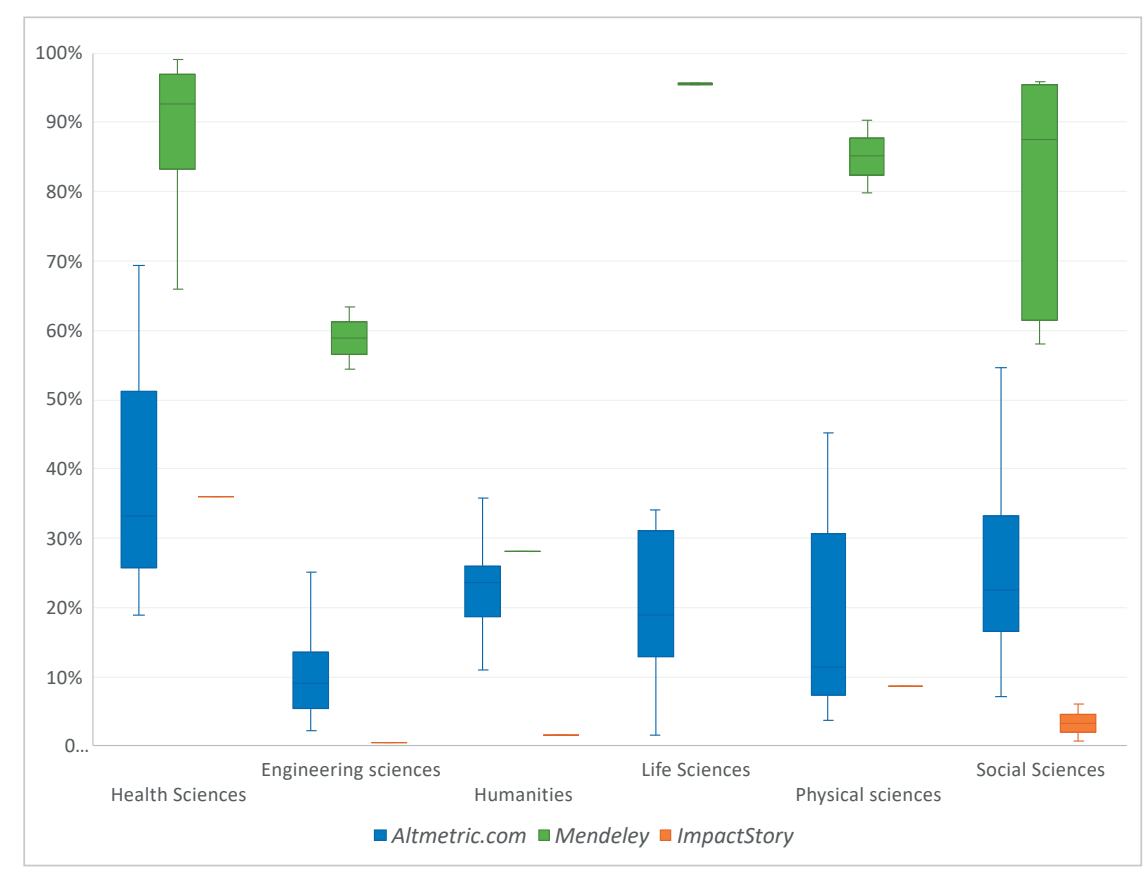

Graph 11. Box plot of the disciplinary coverage of publications by provider 

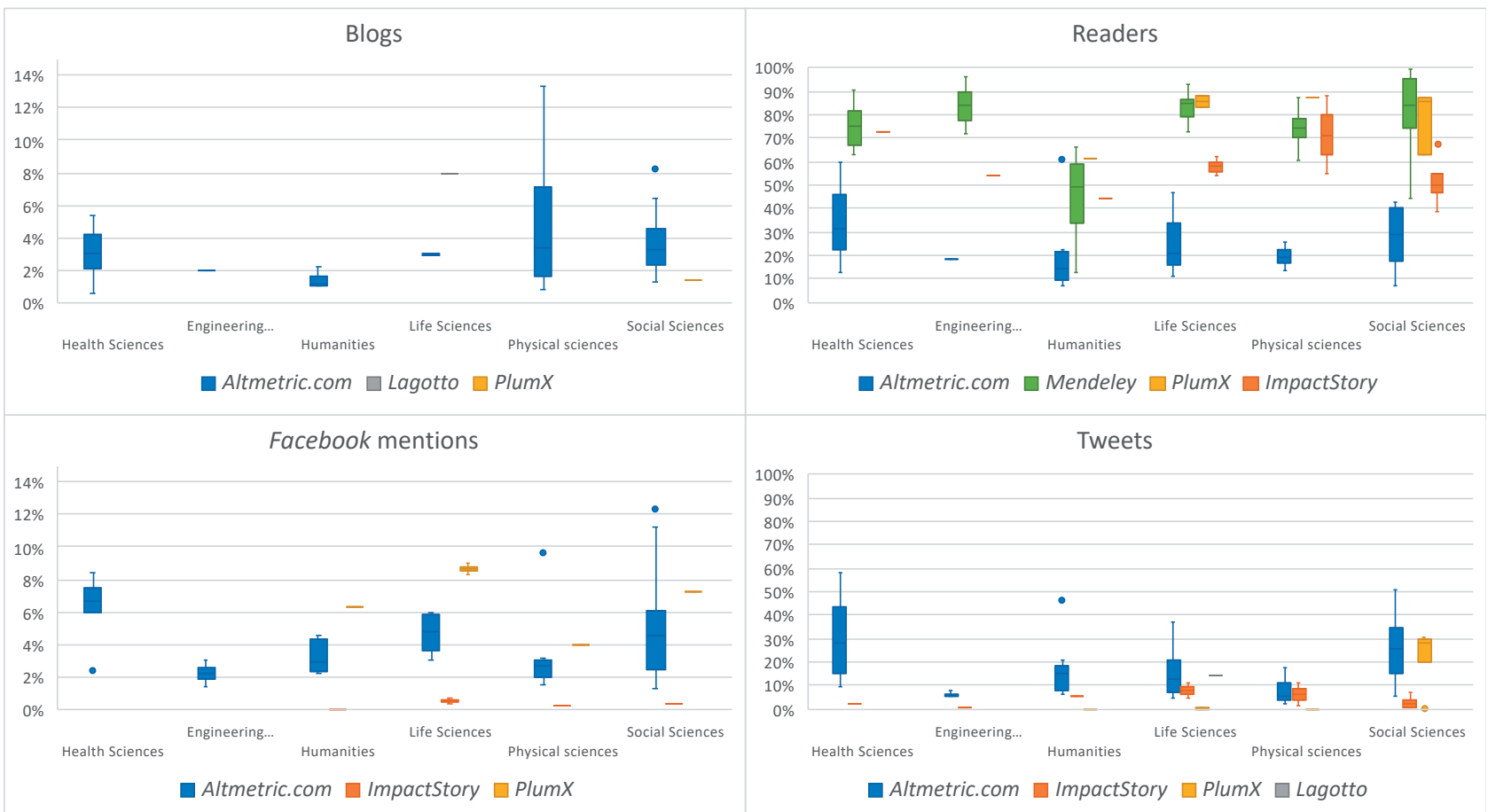

Graph 12. Distribution of the disciplinary coverage of publications by altmetric provider according to four metrics: blogs, Mendeley readers, Facebook mentions and tweets

networks (Haustein et al., 2015; Bar-Ilan et al., 2019). Another reason could be that Mendeley readers could be distributed thematically as bibliometric indicators, owing to the strong correlation between these metrics (Mohammadi; Thelwall, 2014; Mohammadi et al., 2015).

Graph 12 displays the distribution of the percentage of documents mentioned in four metrics: blogs, readers, Facebook mentions and tweets. The remaining metrics were not studied because of the absence of specific data on the coverage of these metrics from a disciplinary perspective. In fact, many of the observations in Graph 12 come from only one or two studies. This lack of data led us to carefully interpret and to limit the analysis to the most studied metrics. For example, the analysis of blogs shows a predominance of Altmetric.com data. In this sense, Physical Sciences (5.3\%) and Social Sciences (3.6\%) are the most mentioned disciplines in blogs according to Altmetric.com. This proportion coincides with the results of Ortega (2019c) about the disciplinary coverage of blog sites, which suggests a strong relation between the mention of articles by discipline and the thematic content of the sources.

Facebook mentions also depicts a majority of Altmetric.com observations, but now the disciplines with a greater mean proportion of mentioned publications are Health Sciences (6.2\%) and Social Sciences (5\%). This raised value for Social Sciences is due to the special presence of Sociology (12.4\%) and Communication (11.2\%) reported by De-Filippo and Sanz-Casado (2018). However, PlumX presents better percentages than Altmetric.com in every metric, particularly for Life Sciences (8.6\%) and Social Sciences (7.3\%) (Peters et al., 2014b).

More data were found for readers. Obviously, Mendeley has a better mean percentage of publications than the other services, but PlumX presents very close percentages, which reveals that PlumX manages better duplicated records and that both services are now integrated into Elsevier's products, sharing bibliographic information. However, data about PlumX are taken only from two works (Peters et al., 2014b; Bar-Ilan et al., 2019), so these results should be read with caution. In general, it is interesting to note that Social Sciences is the discipline with the best coverage in all providers, with the exception of ImpactStory. This important presence of the Social Sciences was previously reported by Haustein et al. (2014b) when they detected $81 \%$ of readers in Psychology; Htoo and $\mathbf{N a ~ ( 2 0 1 5 ) ~ n o t i c e ~ m o r e ~ t h a n ~ d o u b l e ~ t h e ~ n u m - ~}$ ber of readers in Psychology (39\%) than in History (11.8\%) or Linguistics (17.6\%); and Zahedi et al. (2017) perceived that Social Sciences, Humanities (18.1\%), along with Life and Earth Sciences (18.6\%), were the disciplines with more readers.

Finally, the coverage of tweeted papers by discipline presents an unlikely behaviour. In Altmetric.com, Health Sciences $(28 \%)$ and Social Sciences $(24.5 \%)$ are the research categories that attract more tweets on average, whereas ImpactStory, Life Sciences (7.6\%) and Physical Sciences (6\%) are the most tweeted disciplines. PlumX depicts a strong collection of Social Sciences publications $(21.7 \%)$, although this result is obtained at the expense of the absence of more disciplinary data.

\subsection{Comparative}


The existence of different services that provide similar metrics have led to the appearance of some studies that compare coverage and counts between services. However, the number of publications that address this issue is low: only seven studies comparing different providers were located in the literature. The first attempt was performed by Zahedi et al. (2014c) with data from February 2014. They randomly selected 1,000 articles from PLoS one. This sample allowed them to compare Lagotto, Altmetric.com and Mendeley. Their results showed that the data reported by these providers were not consistent and revealed important differences. Mendeley was the service that indexed more publications, Altmetric. com captured more tweets and Lagotto had a special coverage of Facebook mentions. A few months later, Peters et al. (2014b), with data from August 2014, analysed 1,740 publications from the Leibniz Association, a multidisciplinary research organisation from Germany. These publications were searched in four services: Plum Analytics (PlumX), ImpactStory, Altmetric Explorer (Altmetric.com) and Mendeley (through Webometric Analyst). Because the publications could be classified in research areas, they were also able to perform a disciplinary study. The principal result was the verification of the great discrepancy between services, even when using the same sources. In this sense, they evidenced that PlumX barely provided information about tweets, but displayed high scores for Facebook mentions and Mendeley readers. Altmetric.com, on the contrary, was the platform with the best coverage of tweets. From a disciplinary perspective, these authors observed that Science, Technology and Medicine (STM) articles attracted more attention than other disciplines. Kraker et al. (2015) compared two altmetric aggregators: PlumX and ImpactStory, using a small sample of datasets (1000 items) from Figshare. They perceived that PlumX detected considerably more items in social media and also found higher altmetric scores than ImpactStory. In July 2015, Zahedi et al. (2015a) used a random sample of 30,000 articles from Crossref and WoS to check the same providers as in 2014 (Zahedi et al., 2014c). Their results confirmed previous outputs about coverage and metrics. However, this is the first work that explored the counting differences between providers according to the same metric. Thus, they reported that in general Mendeley had a higher number of readers than Lagotto and Altmetric.com, Lagotto counted more Facebook mentions than Altmetric.com, and Altmetric. com collected more tweet counts.

Not until 2018 were there more systematic comparisons between altmetric aggregators. Meschede and Siebenlist (2018), with data from September 2016, analysed 50,000 dois from WoS in Altmetric.com and PlumX. They found that PlumX almost covered $100 \%$ (91\%), while Altmetric.com only collected $38 \%$ of the sample. According to the metrics, publications on Altmetric.com have better scores than PlumX in all the metrics, with the exception of Mendeley readers and Wikipedia citations. From these results, it is interesting to note that Altmetric.com has slightly more papers mentioned in Facebook than PlumX, a result that contradicts other studies (Peters et al., 2014b). In the same year, but with data from May 2017, Ortega (2018b) compared the coverage and counts of 67,000 papers extracted from PlumX in three altmetric data services: Altmetric.com, PlumX and CED. Although the sample could be biased in favour of PlumX, the coverage of Altmetric.com was above $40 \%$, while CED included only $4 \%$ of publications with at least one metric. According to metrics, PlumX (98.6\%) captured more documents with readers than Altmetric.com (95.7\%), but much fewer articles with mentions on Twitter (22.3\%) than Altmetric.com (38\%). This last percentage in PlumX is lower than previous studies (Kraker et al., 2015) but in line with recent analyses (Meschede; Siebenlist, 2018, 21\%; Zahedi; Costas, 2018; 23.9\%). Doubtlessly, the most complete analysis of the coverage of altmetric providers was performed by Zahedi and Costas (2018), who tested 31,000 PLoS one articles in June 2017 on five data platforms: Altmetric.com, CED, Lagotto, PlumX and Mendeley. Despite the fact that using data about only one journal could not be representative, their results were consistent with previous studies, though with higher proportions. Thus, for example, PlumX, Lagotto and Mendeley reached a coverage above $90 \%$, while Altmetric.com obtained $61 \%$ and CED 7\% - a percentage much greater than previous studies (Zahedi et al., 2015a; Ortega, 2018b; Meschede; Siebenlist, 2018). A similar interpretation could be made with the high number of tweeted papers (57\%) in Altmetric.com, much higher than the $38 \%$ of Ortega (2018) and the 36\% of Meschede and Siebenlist (2018). The last study now comparing altmetric aggregators was published by Bar-llan et al. (2019). These authors examined 2,700 articles from the Journal of the Association for Information Science and Technology at two different moments -June 2017 and April 2018- in PlumX, Mendeley and Altmetric.com. The results were very similar to previous studies, confirming that PlumX (87\%) and Mendeley (98.6\%) have almost full coverage of readers. However, it is interesting to note that the number of tweets captured by PlumX (30\%) is close to that of Altmetric.com (35\%), which suggests that PlumX is addressing their disadvantages by capturing tweets.

\section{Limitations}

The realisation of a meta-analysis about the coverage and counting of altmetric providers has evidenced that the reviewed literature presents very different results, showing an elevated variability between similar observations. For example, Graph 2, on the evolution of the different services, depicts wide annual margins in the percentage of covered publications. This instance is perceived in the evolution of the different metrics (reads, tweets, Facebook mentions, etc.). This inaccuracy is mainly caused by the different ways of selecting the sample, which could produce a wide range of biases. For example, the use of some specific sources such as recommended articles from F1000 (Bornmann, 2014 ; 2015; Bornmann; Haunschild, 2015; 2018) or articles from specific journals such as PLoS One (Zahedi et al., 2014c; De-Winter, 2015; Zahedi; Costas, 2018) and Journal of the Association for Information Science and Technology (Bar-Ilan et al., 2019) produce specific results that can hardly be generalised. Another important bias is introduced when local 
studies are analysed, mainly from emergent regions such as Latin America (Maricato; Filho, 2018; Alperin, 2015) or from non-English-speaking countries such as Spain (Torres-Salinas et al., 2016; Torres-Salinas et al., 2018b), Peru (Eléspuru-Briceño; Huaroto, 2016) or China (Wang et al., 2016). The selection of specific formats such as books (Hammarfelt, 2014; Torres-Salinas et al., 2017a; 2017b; Torres-Salinas et al., 2018a) and datasets (Peters et al., 2015; Peters et al., 2016; Kraker et al., 2015) also limits the extrapolation of the results. This does not mean that these studies are biased; on the contrary, they contribute appreciated information about the limitation of altmetrics in specific regions, disciplines or formats. The problem with these results is that they increase variability when a general picture is drawn.

Perhaps, a possible solution would be to exclude those cases. However, this leads us to another significant limitation of this review: the absence of an important critical mass of results. Although this study is based on 107 outputs over seven years, a number far from negligible, many of them present partial analyses or limited information about the data. For example, the average events per publication (Graph 10) or the disciplinary analysis (Graphs 11-12) illustrate some distributions with barely one or two observations, which introduces great randomness and variability, causing the averages to be poorly representative and the trends to present peaks and troughs. Another factor is that many of the referenced studies lack systematic and standardised information on the sample. For instance, some publications do not provide a data extraction date, which hinders result grouping by year. In other cases, there is no clear information about the counts (for example, the percentage of the sample or percentage of the mentioned articles), or the indicators are not well explained or they use particular denominations (i.e. mean available, mean score, intensity). These inaccuracies make it difficult to understand the real meaning of these data, unfortunately leading to some results being discarded for meta-analysis. Finally, another important factor that hinders comparison is the time-window of the samples analysed, because there are important differences in the altmetric impact according to the publication date. This discretionary range of samples introduces more variability in the results.

\section{Discussion}

Despite the limitations mentioned above, this meta-analysis has reported important results about the use, coverage of publications and counting of metrics in the principal altmetric data providers. Altmetric.com is the most used platform for altmetric studies. Graph 1 illustrates how this service is gaining prominence in the scholarly community as an altmetric tool, being used in more than half the reviewed articles (54\%). In fact, $43 \%$ of the articles use Altmetric.com as their only data source. This hegemony of Altmetric.com could be caused by its tendency to support altmetric research with a public API, research grants and a research data program (Altmetric.com, 2019b; 2019c). Another important advantage is that it is the service that captures more events from social networks, especially Twitter (Graph 3), news (Graph 7) and blogs (Graph 8), making this platform the favourite altmetric provider. However, these advantages do not exclude pointing out important limitations as an exclusive source. The most significant is the limitation of indexing only publications mentioned in social networks (Haustein et al., 2015; Bar-Ilan et al., 2019). As a result, only around 30-40\% of the current scientific literature is included in Altmetric.com (Torres-Salinas et al., 2018a; Robinson-García et al., 2018; Didegah et al., 2018; Ortega, 2019). According to the coverage of metrics, Altmetric.com shows the worst performance capturing Mendeley readers (Graph 4), motivated by the non-aggregation of duplicated records (Ortega, 2018b), and the average number of Facebook mentions (Graph 10) due to a restrictive definition of this metric, which only indexes posts on Facebook's public pages (Altmetric Support, 2019).

Mendeley, though it could be considered an altmetric source, is not exactly a data aggregator because it only provides one metric produced by itself. Despite this, it is the second most used source for altmetric studies (18\%). Its importance could be because, for readers, it is the metric that correlates better with citations and has been suggested as an early scientific impact indicator (Mohammadi; Thelwall, 2014; Thelwall; Nevill, 2018). Studies on this source have demonstrated that the coverage of scientific literature is close to $100 \%$, mainly from mid-2014. This source is then widely representative and key to linking impact with the readership of scientific outputs. Its most serious limitation is that there is no integration of duplicated records.

PlumX is the second most used aggregator (17\%) and is becoming the most serious competitor of Altmetric.com, mainly after being acquired by Elsevier (2017). Its principal advantage is the high coverage of publications, over $95 \%$ in recent years (Meschede; Siebenlist, 2018; Zahedi; Costas, 2018; Ortega, 2018a; Ortega, 2019; Gorraiz et al., 2019). This makes PlumX a comprehensive tool that enables tracking the impact of a wide range of materials, especially the performance of books (Torres-Salinas et al., 2017a; 2017b). However, PlumX has difficulties computing some metrics. The number of blogs and news mentions (Graphs 7 and 8), and the proportion of Wikipedia citations is lower than Altmetric.com (Graph 5). Nevertheless, PlumX is making up for these limitations and is improving their figures. A clear example is Twitter mentions. The literature has shown that PlumX initially captured a very low proportion of tweets (Peters et al., 2014b). However, after 2016, when Gnip was used, the proportion increased to more than 20\% (Ortega, 2018b; Meschede; Siebenlist, 2018; Zahedi; Costas, 2018), and today, the latest studies confirm that PlumX gathers as many tweets as Altmetric.com (30\%) (Bar-Ilan et al., 2019). This fact demonstrates the important growth of PlumX as an altmetric provider. In addition, coverage of readers is also noteworthy and is as good as Mendeley due to the 
integration of duplicated records (Peters et al., 2014b; Ortega, 2018b; Bar-Ilan et al., 2019).

Another important result is the decreasing use of ImpactStory and Lagotto. Several reasons explain this disuse. In the case of ImpactStory, this service presents an acceptable proportion of covered documents (60-70\%) (Zahedi et al., 2014b; Peters et al., 2014a; 2014b; Kraker et al., 2015) and a good percentage of Mendeley readers (50-60\%) (Zahedi et al., 2014a; 2014b; Peters et al., 2014b). However, from 2015 their data were not easy to extract (there is no public API), leading to the disappearance of this service in altmetric studies. Lagotto, on the contrary, is scarcely used because it basically covers publications from PLOS. Due to the considerable differences between journals and publishers when they are present on social media (Ortega, 2017), the use of Lagotto introduces important biases. For example, the few studies that used this tool showed a disproportionate coverage of tweets (40-60\%) (Bornmann, 2015; 2014b; De-Winter, 2015; Barthel et al., 2015), Wikipedia citations (4.5\%) (Priem et al., 2012; Bornmann, 2015; Zahedi; Costas, 2018), Facebook mentions (45.4\%) (Zahedi et al., 2014c; Bornmann, 2015) and blogs (9\%) (Fenner, 2013; Bornmann, 2014b). These extreme values are caused by PLoS one, a multidisciplinary journal. These types of journals tend to show very high altmetric scores (Zahedi et al., 2014b).

Nowadays, new open and non-profit services are emerging as data providers that offer raw data about social events (CED, Cobalmetrics). CED is the most promising tool. Although the platform is new (created in 2016) and the coverage of publications is low (10-20\%) (Ortega, 2018a; 2018b; Zahedi; Costas, 2018), it does collect a good proportion of tweets (28.7\%) and Wikipedia citations (31.2\%) (Graph 9). These results confirm the positive development of these open data providers.

\section{Conclusions}

In general, the main lesson that we can extract from this meta-analysis is that the results of using one altmetrics provider or another are very different. The coverage of publications, the selection of sources and the process of extraction and matching of events is so different that the information reported by each service is hardly comparable. The evidences compiled in this study warns of the individual use of only one tool for general altmetrics studies and suggests the use of different platforms to contrast and complement the results. For example, some formats (books and datasets) are unlikely to be covered and display different impact patterns. This limitation is greater with regard to local publications in non-English languages, whose impact is underrepresented by many altmetrics providers. The disparity of counts and sources provided by services reinforces the assumption that different data providers are necessary in order to display a comprehensive view of the altmetric impact of scholarly results.

Furthermore, the analysis performed has pinpointed the advantages and drawbacks of each service, making this study an initial guide to selecting the most appropriate tools for altmetric studies and for tracking the evolution of each platform. The results confirm that Altmetric.com, despite its limited coverage, is the service that captures most mentions from social networks, blogs and news outlets. PlumX has better coverage but captures fewer events than Altmetric. com. The strong point of PlumX is that it is the best service for counting Mendeley readers, in some cases, better than Mendeley itself. CED is a small but promising tool that has a special coverage of mentions from Wikipedia. Lagotto and ImpactStory are gradually falling into disuse because they have limited reach. Lagotto is limited to specific publishers (PLOS), and ImpactStory includes information from other providers (Altmetric.com).

\section{References}

Adams, Jonathan; Loach, Tamar (2015). Digital research report: Altmetric mentions and the communication of medical research. London: Digital Science. ISBN: 9780992947712

Adie, Euan; Roe, William (2013). "Altmetric: enriching scholarly content with article level discussion and metrics". Learned publishing, v. 26, n. 1, pp. 11-17.

https://doi.org/10.1087/20130103

Aduku, Kuku-Joseph; Thelwall, Mike; Kousha, Kayvan (2017). "Do Mendeley reader counts reflect the scholarly impact of conference papers? An investigation of computer science and engineering". Scientometrics, v. 112, n. 1, pp. 573-581. https://doi.org/10.1007/s11192-017-2367-1

Alhoori, Hamed; Furuta, Richard (2014). “Do altmetrics follow the crowd or does the crowd follow altmetrics?". In: Proceedings of the $14^{\text {th }}$ ACM/IEEE-CS Joint conference on digital libraries, pp. 375-378.

Alhoori, Hamed; Choudhury, Sagny-Ray; Kanan, Tarek; Fox, Edward A.; Furuta, Richard; Giles, C. Lee (2015). “On the relationship between open access and altmetrics". In: iConference 2015 proceedings. https://www.ideals.illinois.edu/bitstream/handle/2142/73451/212_ready.pdf

Allen, Polly (2015). To tweet or not to tweet? Is not the question. Plum Analytics. https://plumanalytics.com/to-tweet-or-not-to-tweet-is-not-the-question 
Allen, Polly (2016). PlumX's Facebook Altmetrics - Measure up! Plum Analytics. https://plumanalytics.com/plumx-facebook-altmetrics-measure-up

Allen, Polly (2018). Spanish and Portuguese Wikipedia references are now in PlumX metrics. Plum Analytics. https://plumanalytics.com/spanish-portuguese-wikipedia-references-now-plumx-metrics

Alperin, Juan-Pablo (2015). "Geographic variation in social media metrics: an analysis of Latin American journal articles". Aslib journal of information management, v. 67, n. 3, pp. 289-304.

https://doi.org/10.1108/AJIM-12-2014-0176

Altmetric.com (2019a). Altmetric data timeline.

https://www.altmetric.com/about-our-data/data-timeline

Altmetric.com (2019b). Altmetric annual research grant.

https://www.altmetric.com/research-grant

Altmetric.com (2019c). Researcher data access program.

https://www.altmetric.com/research-access

Altmetric Support (2019). What outputs and sources does Altmetric track?

https://help.altmetric.com/support/solutions/articles/6000060968-what-outputs-and-sources-does-altmetric-track-

Araujo, Amanda-Costa; Nascimento, Dafne-Port; Gonzalez, Gabrielle-Zoldan; Maher, Christopher G.; Costa, Leonardo-Oliveira-Pena (2018). "Impact of low back pain clinical trials measured by the altmetric score: cross-sectional study". Journal of medical Internet research, v. 20, n. 4, e86.

https://doi.org/10.2196/jmir.9368

Bar-Ilan, Judit; Haustein, Stefanie; Peters, Isabella; Priem, Jason; Shema, Hadas; Terliesner, Jens (2012). "Beyond citations: Scholars' visibility on the social web". arXiv preprint, arXiv:1205.5611.

https://arxiv.org/abs/1205.5611

Bar-Ilan, Judit; Halevi, Gali; Milojevic, Staca (2019). "Differences between Altmetric data sources - A case study". Journal of altmetrics, v. 2, n. 1.

https://doi.org/10.29024/joa.4

Barthel, Simon; Tönnies, Sascha; Köhncke, Benjamin; Siehndel, Patrick; Balke, Wolf-Tilo (2015). "What does Twitter measure?: influence of diverse user groups in altmetrics". In: Proceedings of the $15^{\text {th }}$ ACM/IEEE-CS Joint conference on digital libraries, pp. 119-128.

http://www.ifis.cs.tu-bs.de/sites/default/files/JCDL2015_camera-ready.pdf

Bonasio, Alice (2014). Export directly from Scopus and Science Direct! Mendeley blog.

https://blog.mendeley.com/2014/02/03/export-directly-from-scopus-and-science-direct

Bornmann, Lutz (2014a). "Validity of altmetrics data for measuring societal impact: A study using data from Altmetric and F1000Prime". Journal of informetrics, v. 8, n. 4, pp. 935-950.

https://doi.org/10.1016/j.joi.2014.09.007

Bornmann, Lutz (2014b). Which kind of papers has higher or lower altmetric counts? A study using article-level metrics from PLoS and F1000Prime.

http://arxiv. org/abs/1409.2863

Bornmann, Lutz (2014c). "Do altmetrics point to the broader impact of research? An overview of benefits and disadvantages of altmetrics". Journal of informetrics, v. 8, n. 4, pp. 895-903.

https://doi.org/10.1016/j.joi.2014.09.005

Bornmann, Lutz (2015a). "Alternative metrics in scientometrics: A meta-analysis of research into three altmetrics". Scientometrics, v. 103, n. 3, pp. 1123-1144.

https://doi.org/10.1007/s11192-015-1565-y

Bornmann, Lutz (2015b). "Usefulness of altmetrics for measuring the broader impact of research: A case study using data from PLoS and F1000Prime". Aslib journal of information management, v. 67, n. 3, pp. 305-319.

https://doi.org/10.1108/AJIM-09-2014-0115

Bornmann, Lutz; Haunschild, Robin (2016a). "How to normalize Twitter counts? A first attempt based on journals in the Twitter Index". Scientometrics, v. 107, n. 3, pp. 1405-1422.

https://doi.org/10.1007/s11192-016-1893-6 
Bornmann, Lutz; Haunschild, Robin (2016b). "Overlay maps based on Mendeley data: The use of altmetrics for readership networks". Journal of the Association for Information Science and Technology, v. 67, n. 12, pp. 3064-3072. https://doi.org/10.1002/asi.23569

Bornmann, Lutz; Haunschild, Robin (2017). “Measuring field-normalized impact of papers on specific societal groups: An altmetrics study based on Mendeley data". Research evaluation, v. 26, n. 3, pp. 230-241.

https://doi.org/10.1093/reseval\%2Frvx005

Bornmann, Lutz; Haunschild, Robin (2018a). "Do altmetrics correlate with the quality of papers? A large-scale empirical study based on F1000Prime data". PLoS one, v. 13, n. 5, pp. e0197133.

https://doi.org/10.1371/journal.pone.0197133

Bornmann, Lutz; Haunschild, Robin (2018b). "Normalization of zero-inflated data: An empirical analysis of a new indicator family and its use with altmetrics data". Journal of informetrics, v. 12, n. 3, pp. 998-1011.

https://doi.org/10.1016/j.joi.2018.01.010

Costas, Rodrigo; Zahedi, Zoreh; Wouters, Paul (2015a). “Do 'altmetrics' correlate with citations? Extensive comparison of altmetric indicators with citations from a multidisciplinary perspective". Journal of the Association for Information Science and Technology, v. 66, n. 10, pp. 2003-2019.

https://doi.org/10.1002/asi.23309

Costas, Rodrigo; Zahedi, Zoreh; Wouters, Paul (2015b). "The thematic orientation of publications mentioned on social media: large-scale disciplinary comparison of social media metrics with citations". Aslib journal of information management, v. 67, n. 3, pp. 260-288.

https://doi.org/10.1108/ajim-12-2014-0173

D’Angelo, Ciriaco-Andrea; Di-Russo, Samuele (2019). "Testing for universality of Mendeley readership distributions". Journal of informetrics, v. 13, n. 2, pp. 726-737.

https://doi.org/10.1016/j.joi.2019.03.011

Dardas, Latefa-Ali; Woodward, Amanda; Scott, Jewel; Xu, Hanzhang; Sawair, Faleh A. (2018). "Measuring the social impact of nursing research: An insight into altmetrics". Journal of advanced nursing, v. 75, n. 7, pp. 1394-1405. https://doi.org/10.1111/jan.13921

De-Filippo, Daniela; Sanz-Casado, Elías (2018). "Bibliometric and altmetric analysis of three social science disciplines". Frontiers in research metrics and analytics, v. 3, n. 34.

https://doi.org/10.3389/frma.2018.00034

De-Winter, Joost C. (2015). "The relationship between tweets, citations, and article views for PLoS one articles". Scientometrics, v. 102, n. 2, pp. 1773-1779.

https://doi.org/10.1007/s11192-014-1445-x

Didegah, Fereshteh; Bowman, Timothy D.; Holmberg, Kim (2016). “Increasing our understanding of altmetrics: identifying factors that are driving both citation and altmetric counts". In: IConference 2016 proceedings.

http://hdl.handle.net/2142/89331

Eléspuru Briceño, Liliana; Huaroto, Libio (2016). "Los repositorios institucionales como herramientas para medir los indicadores Altmetrics: experiencia de la Universidad Peruana de Ciencias Aplicadas (UPC)". In: Congreso internacional de bibliotecas universitarias 2016 (CIBU).

https://repositorioacademico.upc.edu.pe/bitstream/handle/10757/617434/repositorios_institucionales_altmetric_ elespuru_huaroto.pdf

Erdt, Mojisola; Aw, Ashley-Sara; Aung, Htet-Htet; Mohammadi, Ehsan; Theng, Yin-Leng (2016a). "Investigating Singapore's altmetric landscape". In: Proceedings of the $79^{\text {th }}$ ASIS\&T Annual meeting: Creating knowledge, enhancing lives through information \& technology, p. 29.

https://doi.org/10.1002/pra2.2016.14505301029

Erdt, Mojisola; Nagarajan, Aarthy; Sin, Sei-Ching J.; Theng, Yin-Leng (2016b). "Altmetrics: an analysis of the state-ofthe-art in measuring research impact on social media". Scientometrics, v. 109, n. 2, pp. 1117-1166.

https://doi.org/10.1007/s11192-016-2077-0

Fairclough, Ruth; Thelwall, Mike (2015). "National research impact indicators from Mendeley readers". Journal of informetrics, v. 9, n. 4, pp. 845-859.

https://doi.org/10.1016/j.joi.2015.08.003

Fang, Zhichao; Costas, Rodrigo (2018). "Studying the Velocity Index for various Altmetric.com data sources". In: 23 ${ }^{\text {rd }}$ International conference on science and technology indicators (STI 2018).

http://hdl.handle.net/1887/65278 
Fenner, Martin (2013). “What can article-level metrics do for you?”. PLoS biology, v. 11, n. 10, e1001687. https://doi.org/10.1371/journal.pbio.1001687

Gorraiz, Juan; Blahous, Benedikt; Wieland, Martin (2018). “Monitoring the broader impact of the journal publication output on country level: A case study for Austria". In: International workshop on altmetrics for research outputs measurements and scholarly information management.

https://doi.org/10.1007/978-981-13-1053-9_4

Hammarfelt, Björn (2014). "Using altmetrics for assessing research impact in the humanities". Scientometrics, v. 101, n. 2, pp. 1419-1430.

https://doi.org/10.1007/s11192-014-1261-3

Hassan, Saeed-UI; Gillani, Uzair A. (2016). "Altmetrics of 'altmetrics' using Google Scholar, Twitter, Mendeley, Facebook, Google-plus, CiteULike, Blogs and Wiki". arXiv preprint arXiv:1603.07992.

https://arxiv.org/abs/1603.07992

Hassan, Saeed-UI; Imran, Mubashir; Gillani, Uzair A.; Aljohani, Naif-Radi; Bowman, Timothy D.; Didegah, Fereshteh (2017). "Measuring social media activity of scientific literature: an exhaustive comparison of Scopus and novel altmetrics big data". Scientometrics, v. 113, n. 2, pp. 1037-1057.

https://doi.org/10.1007/s11192-017-2512-x

Haustein, Stefanie; Bowman, Timothy D.; Macaluso, Benoît; Sugimoto, Cassidy R.; Larivière, Vincent; Borner, Katie (2014a). "Measuring Twitter activity of arXiv e-prints and published papers". In: Proc. Altmetrics14: expanding impacts and metrics.

https://figshare.com/articles/Measuring_Twitter_activity_of_arXiv_e_prints_and_published_papers/1041514

Haustein, Stefanie; Costas, Rodrigo; Larivière, Vincent (2015). “Characterizing social media metrics of scholarly papers: The effect of document properties and collaboration patterns". PLoS one, v. 10, n. 3, e0120495.

https://doi.org/10.1371/journal.pone.0120495

Haustein, Stefanie; Larivière, Vincent (2014). "Mendeley as a source of readership by students and postdocs? Evaluating article usage by academic status". In: Proceedings of the IATUL conferences, paper 2.

https://docs.lib.purdue.edu/iatul/2014/altmetrics/2

Haustein, Stefanie; Larivière, Vincent; Thelwall, Mike; Amyot, Didier; Peters, Isabella (2014b). "Tweets vs. Mendeley readers: How do these two social media metrics differ?" IT-Information technology, v. 56, n. 5, pp. 207-215.

https://doi.org/10.1515/itit-2014-1048

Haustein, Stefanie; Peters, Isabella; Bar-Ilan, Judit; Priem, Jason; Shema, Hema; Terliesner, Jens (2014c). "Coverage and adoption of altmetrics sources in the bibliometric community". Scientometrics, v. 101, n. 2, pp. 1145-1163.

https://doi.org/10.1007/s11192-013-1221-3

Haustein, Stefanie; Peters, Isabella; Sugimoto, Cassidy R.; Thelwall, Mike; Larivière, Vincent (2014d). "Tweeting biomedicine: An analysis of tweets and citations in the biomedical literature". Journal of the Association for Information Science and Technology, v. 65, n. 4, pp. 656-669.

https://doi.org/10.1002/asi.23101

Holmberg, Kim; Park, Han-Woo (2018). "An altmetric investigation of the online visibility of South Korea-based scientific journals". Scientometrics, v. 117, n. 1, pp. 603-613.

https://doi.org/10.1007/s11192-018-2874-8

Htoo, Tint-Hla-Hla; Na, Jin-Cheon (2015). “Comparison of altmetrics across multiple disciplines: Psychology, history, and linguistics". In: $4^{\text {th }}$ International conference of Asian Special Libraries (ICOASL 2015).

https://ink.library.smu.edu.sg/library_research/50

Htoo, Tint-Hla-Hla; Na, Jin-Cheon (2017). "Disciplinary differences in altmetrics for social sciences". Online information review, v. 41, n. 2, pp. 235-251.

https://doi.org/10.1108/oir-12-2015-0386

ImpactStory (2019). ImpactStory: Discover the online impact of your research. https://profiles.impactstory.org/search

Jabaley, Craig S.; Groff, Robert F.; Stentz, Michael J.; Moll, Vanessa; Lynde, Grant C.; Blum, James M.; O’Reilly-Shah, Vikas N. (2018). "Highly visible sepsis publications from 2012 to 2017: Analysis and comparison of altmetrics and bibliometrics". Journal of critical care, v. 48, pp. 357-371.

https://doi.org/10.1016/j.jcrc.2018.09.033 
Joubert, Marina; Costas, Rodrigo (2019). "Getting to know science tweeters: A pilot analysis of South African Twitter users tweeting about research articles". Journal of altmetrics, v. 2, n. 1.

https://doi.org/10.29024/joa.8

Knight, Simon R. (2014). "Social media and online attention as an early measure of the impact of research in solid organ transplantation". Transplantation, v. 98, n. 5, pp. 490-496.

https://doi.org/10.1097/tp.0000000000000307

Kolahi, Jafar; Iranmanesh, Pouya; Khazaei, Saber (2017). "Altmetric analysis of 2015 dental literature: a cross sectional survey". British dental journal, v. 222, n. 9, pp. 695.

https://doi.org/10.1038/sj.bdj.2017.408

Kousha, Keyvan; Thelwall, Mike (2017). "Are Wikipedia citations important evidence of the impact of scholarly articles and books?". Journal of the Association for Information Science and Technology, v. 68, n. 3, pp. 762-779.

https://doi.org/10.1002/asi.23694

Kraker, Peter; Lex, Elisabeth; Gorraiz, Juan; Gumpenberger, Christian; Peters, Isabella (2015). “Research data explored II: The anatomy and reception of Figshare". arXiv preprint, arXiv:1503.01298.

https://arxiv.org/abs/1503.01298

Luo, Feighen; Sun, Aixin; Erdt, Mojisola; Raamkumar, Aravind S.; Theng, Yin L. (2018). “Exploring prestigious citations sourced from top universities in bibliometrics and altmetrics: a case study in the computer science discipline". Scientometrics, v. 114, n. 1, pp. 1-17.

https://doi.org/10.1007/s11192-017-2571-z

Maggio, Lauren A.; Leroux, Todd C.; Meyer, Holly S.; Artino Jr, Anthony R. (2018). “\#MedEd: exploring the relationship between altmetrics and traditional measures of dissemination in health professions education". Perspectives on medical education, v. 7, n. 4, pp. 239-247.

https://doi.org/10.1007/s40037-018-0438-5

Maricato, João-De-Melo; Filho, Jayme-Leiro-Vilan (2018). "The potential for altmetrics to measure other types of impact in scientific production: academic and social impact dynamics in social media and networks". Information research, v. 23, n 1.

http://www.informationr.net/ir/23-1/infres231.html

Mas-Bleda, Amalia; Thelwall, Mike (2016). "Can alternative indicators overcome language biases in citation counts? A comparison of Spanish and UK research". Scientometrics, v. 109, n. 3, pp. 2007-2030.

https://doi.org/10.1007/s11192-016-2118-8

Meschede, Christine; Siebenlist, Tobias (2018). "Cross-metric compatability and inconsistencies of altmetrics". Scientometrics, v. 115, n. 1, pp. 283-297.

https://doi.org/10.1007/s11192-018-2674-1

Mohammadi, Ehsan; Thelwall, Mike (2014). “Mendeley readership altmetrics for the social sciences and humanities: Research evaluation and knowledge flows". Journal of the Association for Information Science and Technology, v. 65, n. 8, pp. 1627-1638.

https://doi.org/10.1002/asi.23071

Mohammadi, Ehsan; Thelwall, Mike; Haustein, Stefanie; Larivière, Vincent (2015). "Who reads research articles? An altmetrics analysis of Mendeley user categories". Journal of the Association for Information Science and Technology, v. 66, n. 9, pp. 1832-1846.

https://doi.org/10.1002/asi.23286

NISO (2016). Outputs of the NISO alternative assessment metrics project. NISO RP-25-2016.

https://bit.ly/2SXCEym

Nuredini, Kaltrina; Peters, Isabella (2016). "Enriching the knowledge of altmetrics studies by exploring social media metrics for Economic and Business Studies journals". In: Proceedings of the $21^{\text {st }}$ International conference on science and technology indicators (S\&T Indicators).

https://www.econstor.eu/bitstream/10419/146879/1/enriching-knowledge-altmetrics-economic-business-studies-journals.pdf https://ideas.repec.org/p/zbw/esconf/146879.html

Orduña-Malea, Enrique; Delgado-López-Cózar, Emilio (2019). “Demography of altmetrics under the light of Dimensions: Locations, institutions, journals, disciplines and funding bodies in the global research framework. Journal of altmetrics, v. 2 , n. 1, p. 3.

https://doi.org/10.29024/joa.13 
Ortega, José-Luis (2016a). Social network sites for scientists: A quantitative survey. Oxford, UK: Chandos Publishing (Elsevier Group), 198 pp. ISBN: 9780081005927

Ortega, José-Luis (2016b). "To be or not to be on Twitter, and its relationship with the tweeting and citation of research papers". Scientometrics, v. 109, n. 2, pp. 1353-1364.

https://doi.org/10.1007/s11192-016-2113-0

Ortega, José-Luis (2017). "The presence of academic journals on Twitter and its relationship with dissemination (tweets) and research impact (citations)". Aslib journal of information management, v. 69, n. 6, pp. 1-15.

https://doi.org/10.1108/ajim-02-2017-0055

Ortega, José-Luis (2018a). "Disciplinary differences of the impact of altmetric". FEMS microbiology letters, v. 365, n. 7, fny049.

https://doi.org/10.1093/femsle/fny049

Ortega, José-Luis (2018b). "Reliability and accuracy of altmetric providers: a comparison among Altmetric.com, PlumX and Crossref Event Data". Scientometrics, v. 116, n. 3, pp. 2123-2138.

https://doi.org/10.1007/s11192-018-2838-z

Ortega, José-Luis (2019a). "The coverage of blogs and news in the three major altmetric data providers". In: $17^{\text {th }}$ International conference of the International Society for Scientometrics and Informetrics, Rome, Italy.

https://osf.io/8xqjn

Ortega, José-Luis (2019b). "Availability and audit of links in altmetric data providers: link checking of blogs and news in Altmetric.com, Crossref Event Data and PlumX". Journal of altmetrics, v. 2, n. 1, pp. 4.

https://doi.org/10.29024/joa.14

Ortega, José-Luis (2019c). "Blogs and news sources coverage in altmetrics data providers: A comparative analysis by country, language, and subject".

https://osf.io/z5x86

Peters, Isabella; Jobmann, Alexandra; Eppelin, Anita; Hoffmann, Christian P.; Künne, Sylvia; Wollnik-Korn, Gabriele (2014a). "Altmetrics for large, multidisciplinary research groups: A case study of the Leibniz Association". In: Libraries in the digital age (LIDA) Proceedings, p. 13.

http://ozk.unizd.hr/lida/files/LIDA_2014_Proceedings.pdf

Peters, Isabella; Jobmann, Alexandra; Hoffmann, Christian P.; Künne, Sylvia; Schmitz, Jasmin; Wollnik-Korn, Gabriele (2014b). "Altmetrics for large, multidisciplinary research groups: Comparison of current tools". Bibliometrie-praxis und forschung, v. 3.

https://doi.org/10.5283/bpf.205

Peters, Isabella; Kraker, Peter; Lex, Elisabeth; Gumpenberger, Christian; Gorraiz, Juan (2015). “Research data explored: Citations versus altmetrics". arXiv preprint, arXiv:1501.03342.

https://arxiv.org/ftp/arxiv/papers/1501/1501.03342.pdf

Peters, Isabella; Kraker, Peter; Lex, Elisabeth; Gumpenberger, Christian; Gorraiz, Juan (2016). "Research data explored: An extended analysis of citations and altmetrics". Scientometrics, v. 107, n. 2, pp. 723-744.

https://doi.org/10.1007/s11192-016-1887-4

PLoS (2019). Article-level metrics > Sources > Facebook.

https://alm.plos.org/docs/facebook

Plum Analytics (2019). "Coverage: Expanding the world of altmetrics”. Plum Analytics.

https://plumanalytics.com/learn/about-metrics/coverage

Pooladian, Aida; Borrego, Ángel (2016). "A longitudinal study of the bookmarking of library and information science literature in Mendeley". Journal of informetrics, v. 10, n. 4, pp. 1135-1142.

https://doi.org/10.1016/j.joi.2016.10.003

Priem, Jason; Piwowar, Heather; Hemminger, Bradley M. (2012). "Altmetrics in the wild: Using social media to explore scholarly impact". arXiv preprint, arXiv:1203.4745.

https://arxiv.org/abs/1203.4745

Repiso, Rafael; Castillo, Antonio; Torres-Salinas, Daniel (2019). "Altmetrics, alternative indicators for Web of Science communication studies journals". Scientometrics, v. 119, n. 2, pp. 941-958.

https://doi.org/10.1007/s11192-019-03070-7 
Robinson-García, Nicolás; Arroyo-Machado, Wenceslao; Moed, Henk; Torres-Salinas, Daniel (2018). "Do altmetrics promote open access? An exploratory analysis on altmetric differences between types of access in the field of Physics". In: $23^{\text {rd }}$ International conference on science and technology indicators (STI 2018).

https://doi.org/10.5281/zenodo.1414022

Robinson-García, Nicolás; Arroyo-Machado, Wenceslao; Torres-Salinas, Daniel (2019). "Mapping social media attention in Microbiology: Identifying main topics and actors". FEMS microbiology letters, v. 366, n. 7, fnz075.

https://doi.org/10.1093/femsle/fnz075

Robinson-García, Nicolás; Torres-Salinas, Daniel; Zahedi, Zohreh; Costas, Rodrigo (2014). “New data, new possibilities: Exploring the insides of Altmetric.com". El profesional de la información, v. 23, n. 4, pp. 1386-6710.

https://doi.org/10.3145/epi.2014.jul.03

Rosenkrantz, Andrew B.; Ayoola, Abimbola; Singh, Kush; Duszak Jr, Richard (2017). "Alternative metrics ('altmetrics') for assessing article impact in popular general radiology journals". Academic radiology, v. 24, n. 7, pp. 891-897.

https://doi.org/10.1016/j.acra.2016.11.019

Scopus (2014) "Mendeley readership statistics available in Scopus". Scopus blog.

https://blog.scopus.com/posts/mendeley-readership-statistics-available-in-scopus

Scott, Catriona; Farrow, Paul; Young, Fran (2015). "Use of Twitter and other social media to disseminate specialist clinical research: analysis using Altmetric". Current medical research and opinion, v. 31, suppl. 1, S18.

https://doi.org/10.1185/03007995.2015.1021578

Thelwall, Mike (2018). "Altmetric prevalence in the social sciences, arts and humanities: Where are the online discusions?". Journal of altmetrics, v. 1, n. 1.

https://doi.org/10.29024/joa.6

Thelwall, Mike; Nevill, Tamara (2018). “Could scientists use Altmetric.com scores to predict longer term citation counts?". Journal of informetrics, v. 12, n. 1, pp. 237-248.

https://doi.org/10.1016/j.joi.2018.01.008

Thelwall, Mike; Wilson, Paul (2016). "Mendeley readership altmetrics for medical articles: An analysis of 45 fields". Journal of the Association for Information Science and Technology, v. 67, n. 8, pp. 1962-1972.

https://doi.org/10.1002/asi.23501

Torres-Salinas, Daniel; Castillo-Valdivieso, Pedro-Ángel; Pérez-Luque, Álvaro; Romero-Frías, Esteban (2018b). “Altmétricas a nivel institucional: visibilidad en la Web de la producción científica de las universidades españolas a partir de Altmetric.com". El profesional de la información, v. 27, n. 3, pp. 483-492.

https://doi.org/10.3145/epi.2018.may.03

Torres-Salinas, Daniel; Gorraiz, Juan; Robinson-García, Nicolás (2018a). "The insoluble problems of books: what does Altmetric.com have to offer?". Aslib journal of information management, v. 70, n. 6, pp. 691-707.

https://doi.org/10.1108/AJIM-06-2018-0152

Torres-Salinas, Daniel; Gumpenberger, Christian; Gorraiz, Juan (2017b). "PlumX as a potential tool to assess the macroscopic multidimensional impact of books". Frontiers in research metrics and analytics, v. 2, n. 5.

https://doi.org/10.3389/frma.2017.00005

Torres-Salinas, Daniel; Milanés-Guisado, Yusnelkis (2014). “Presencia en redes sociales y altmétricas de los principales autores de la revista El profesional de la información". El profesional de la información, v. 23, n. 4, pp. $367-372$.

https://doi.org/10.3145/epi.2014.jul.04

Torres-Salinas, Daniel; Robinson-García, Nicolás; Gorraiz, Juan (2017a). "Filling the citation gap: measuring the multidimensional impact of the academic book at institutional level with PlumX". Scientometrics, v. 113, n. 3, pp. 1371-1384. https://doi.org/10.1007/s11192-017-2539-z

Torres-Salinas, Daniel; Robinson-García, Nicolás; Jiménez-Contreras, Evaristo (2016). "Can we use altmetrics at the institutional level? A case study analysing the coverage by research areas of four Spanish universities". In: $21^{\text {st }}$ International conference on science and technology indicators-STI 2016.

https://arxiv.org/abs/1606.00232

Van-Honk, Jeroen; Costas, Rodrigo (2016). “Integrating context in Twitter metrics: Preliminary investigation on the possibilities of hashtags as an altmetric resource”. In: Altmetrics16. Moving beyond counts: integrating context, pp. 1-7. http://altmetrics.org/wp-content/uploads/2016/09/altmetrics16_paper_5.pdf 
Wang, Xianwen; Fang, Zhichao; Li, Qingchun; Guo, Xinhui (2016). "The poor altmetric performance of publications authored by researchers in mainland China". Frontiers in research metrics and analytics, v. 1, n. 8.

https://doi.org/10.3389/frma.2016.00008

Wang, Xianwen; Liu, Chen; Fang, Zhichao; Mao, Wenli (2014). "From attention to citation, what and how does altmetrics work?". arXiv preprint, arXiv:1409.4269.

https://arxiv.org/abs/1409.4269

Williams, Catherine (2015). "Altmetric to provide expanded mainstream media tracking". Altmetric blog. https://www.altmetric.com/blog/moreover

Wolcott, Holly; Williams, Duane; Antman, Melissa; Corrigan, James; Burgess, Christine (2019). "Can altmetrics supplement citation analysis for funding program evaluation? Altmetric analyses of National Cancer Institute (NCl) extramural divisions". In: Proceedings of the $17^{\text {th }}$ International conference on scientometrics \& informetrics, v. 2, Rome, pp. $235-240$. http://issi-society.org/proceedings/issi_2019/ISSI\%202019\%20-\%20Proceedings\%20VOLUME\%20II.pdf

Wooldridge, Jenny; King, Mike B. (2019). "Altmetric scores: An early indicator of research impact". Journal of the Association for Information Science and Technology, v. 70, n. 3, pp. 271-282.

https://doi.org/10.1002/asi.24122

Yu, Houqiang (2017). "Context of altmetrics data matters: an investigation of count type and user category". Scientometrics, v. 111, n. 1, pp. 267-283.

https://doi.org/10.1007/s11192-017-2251-z

Yu, Houqiang; Xu, Shenmeng; Xiao, Tingting; Hemminger, Bradley M.; Yang, Siluo (2017). "Global science discussed in local altmetrics: Weibo and its comparison with Twitter". Journal of informetrics, v. 11, n. 2, pp. 466-482.

https://doi.org/10.1016/j.joi.2017.02.011

Zahedi, Zohreh; Costas, Rodrigo (2018). "General discussion of data quality challenges in social media metrics: Extensive comparison of four major altmetric data aggregators". PloS one, v. 13, n. 5, e0197326.

https://doi.org/10.1371/journal.pone.0197326

Zahedi, Zohreh; Costas, Rodrigo; Wouters, Paul (2014a). "Assessing the impact of the publications read by the different Mendeley users: Is there any different pattern among users?". In: Proceedings of the IATUL conferences, 2014 IATUL proceedings.

http://hdl.handle.net/1887/46944

Zahedi, Zohreh; Costas, Rodrigo; Wouters, Paul (2014b). "How well developed are altmetrics? A cross-disciplinary analysis of the presence of 'alternative metrics' in scientific publications". Scientometrics, v. 101, n. 2, pp. $1491-1513$. https://doi.org/10.1007/s11192-014-1264-0

Zahedi, Zohreh; Fenner, Martin; Costas, Rodrigo (2014c). “How consistent are altmetrics providers? Study of 1000 PLoS one publications using the PLoS alm, Mendeley and Altmetric.com APIs". In: Altmetrics 14. Workshop at the web science conference, Bloomington, USA.

https://bit.ly/2Qsv5OK

Zahedi, Zohreh; Fenner, Martin; Costas, Rodrigo (2015). "Consistency among altmetrics data provider/aggregators: What are the challenges?". In: Altmetrics workshop, 9 October 2015, Amsterdam Science Park, Amsterdam.

https://altmetrics.org/wp-content/uploads/2015/09/altmetrics15_paper_14.pdf

Zahedi, Zohreh; Haustein, Stefanie; Bowman, Timothy (2014d). "Exploring data quality and retrieval strategies for Mendeley reader counts". In: SIG/MET workshop, ASIS\&T 2014 annual meeting, Seattle.

http://www.asis.org/SIG/SIGMET/data/uploads/sigmet2014/Zahedi.pdf

Zahedi, Zohreh; Van-Eck, Nees J. (2018). “Exploring topics of interest of Mendeley users”. Journal of altmetrics, v. 1, n. 1. https://doi.org/10.29024/joa.7

Zhang, Xi; Wang, Xianhai; Zhao, Hongke; Ordóñez-De-Pablos, Patricia; Sun, Yongqiang; Xiong, Hui (2019). “An effectiveness analysis of altmetrics indices for different levels of artificial intelligence publications". Scientometrics, v. 119, n. 3, pp. 1-34.

https://doi.org/10.1007/s11192-019-03088-x 